Bio - grafía. Escritos sobre la Biología y su Enseñanza. ISSN 2027-1034

Edición Extraordinaria. p.p. 44 - 83

Memorias del IX Encuentro Nacional de Experiencias en Enseñanza de la Biología y la Educación Ambiental. IV Congreso Nacional de Investigación en Enseñanza de la Biología.

\title{
LAILUSTRACIÓN CIENTÍFI CA DE INSECTOS COMO ESTRATEGIA PED AGÓGICA PARA LA VALORACIÓN Y CUIDADO DE LA BIODIVERSIDAD
}

\section{SCIENTIFIC ILLUSTRATION OF INSECTS AS A PEDAGOGICAL STRATEGY FOR THE ASSESSMENT AND CARE OF BIODIVERSTYY}

\section{Lorena Guerrero Felix ${ }^{1}$}

\section{RESUMEN}

Este trabajo tiene como objetivo desarrollar una estrategia pedagógica para la valoración y cuidado de la biodiversidad usando como medio la ilustración científica de insectos, se abordan conceptos fundamentales como taxonomía, morfo-fisiología, ecología, y ciclo de vida, para facilitar procesos de comprensión sobre los valores intrínsecos, instrumentales y emocionales asociados a la biodiversidad, esta estrategia está siendo implementada con los con estudiantes del curso 804 y maestros de biología y artes del Colegio CEDID Ciudad Bolívar en el barrio Sierra Morena (Ciudad Bolívar).

Para llevar a cabo este proyecto se diseñaron e implementaron instrumentos de recolección de información propios de la investigación- acción, como son la entrevista semiestructurada, las encuestas, y el diario de campo, el proceso en general fue orientado por el modelo pedagógico y didáctico Enseñanza para la Comprensión (EpC) necesario para la reformulación y diseño de las sesiones y de las rúbricas de evaluación.

Las principales estrategias metodológicas han sido: reuniones con profesores de biología y artes, trabajo de campo en la huerta, consultas teóricas, recolección e identificación de insectos, prácticas de laboratorio, y conocimiento y aplicación de las técnicas de ilustración, para dar como resultado una bitácora de ilustraciones científicas de insectos. Este proyecto busca confirmar que los estudiantes pueden comprender la importancia de valorar y cuidar la biodiversidad por medio del conocimiento de los insectos presentes en su entorno, posicionando la huerta como un escenario óptimo para la enseñanza de la biología, y reconocer la ilustración científica como una estrategia pedagógica eficaz que permite que tanto estudiantes como maestros construyan conocimiento y establezcan relaciones entre ellos y con el ambiente.

PALABRAS CLAVE: llustración científica de insectos, Estrategia Pedagógica, Valoración y Cuidado de la Biodiversidad, Enseñanza para la Comprensión.

\footnotetext{
${ }^{1}$ Estudiante de Licenciatura en Biología de la Universidad Pedagógica Nacional, Facultad de Ciencia y Tecnología, Departamento de Biología.
} 
Bio - grafía. Escritos sobre la Biología y su Enseñanza. ISSN 2027-1034

Edición Extraordinaria. p.p. 44 - 83

Memorias del IX Encuentro Nacional de Experiencias en Enseñanza de la Biología y la Educación Ambiental. IV Congreso Nacional de Investigación en Enseñanza de la Biología.

\begin{abstract}
This work is being carried out with the objective of developing a pedagogical strategy for the assessment and care of the biodiversity using the means of the scientific illustration of the insects, to develop the fundamental concepts such as taxonomy, morphologyphysiology, ecology, and cycle of life, To develop scientific abilities and comprehension processes on the intrinsic, instrumental and emotional assessment associated to biodiversity, favoring the care of the same, this strategy is being implemented with students of course 804 and teachers of biology and arts of the Colegio CEDID Ciudad Bolívar in the neighborhood Sierra Morena (Ciudad Bolívar, Bogota). To carry out this project, information collection instruments were designed and implemented, such as the semi-structured interview, the surveys, and the field diary. In general, the process was guided by the pedagogical and didactic model teaching for the Comprehension (EpC) necessary for the reform and design of the sessions and evaluation rubrics. The main methodological strategies used were: field work in the orchard, theoretical consultations, insect collection and identification, laboratory practices, and the knowledge and application of illustration techniques, to produce a log of illustrations of insects. It is hoped that this project will confirm that students can understand the importance of assessment and caring for biodiversity through knowledge of the insects present in their environment, positioning the orchard as an optimal scenario for teaching biology, and recognize the illustration scientific as an effective pedagogical strategy that allows both students and teachers to build knowledge and establish relationships between them and the environment.
\end{abstract}

KEYWORDS: Scientific illustration of insects, Pedagogical Strategy, Biodiversity Assessment and Care, Teaching for Understanding.

\title{
INTRODUCCIÓN
}

La investigación que aquí se presenta nace a partir de la práctica pedagógica que está siendo desarrollada en la línea de investigación Biodiversidad, Biotecnología y Conservación, del Departamento de Biología de la Universidad Pedagógica Nacional, en la cual, y según el Reglamento de Práctica Pedagógica del Proyecto Curricular de la Licenciatura en Biología, se concibe como un espacio de reflexión-acción e investigación, en torno a la innovación, indagación y recontextualización de los saberes desde enfoques éticos, estéticos, cognitivos, pedagógicos y didácticos, en función de la formación profesional e Integral del Maestro en Formación (Consejo Académico de la Universidad Pedagógica Nacional, 2013).

En respuesta a ello, se propuso la realización de una bitácora de ilustraciones científicas de insectos durante los meses de septiembre del 2016 hasta septiembre del 2017, como ejercicio de memoria, expresión e identidad de los estudiantes del curso 804 del Colegio CEDID Ciudad Bolívar, para aportar al reconocimiento de la biodiversidad presente en su colegio, teniendo en cuenta que el arte en materia cognitiva como fuente activa de percepción, conocimiento y comprensión permite a los estudiantes realizar procesos 


\title{
Bio - grafía. Escritos sobre la Biología y su Enseñanza. ISSN 2027-1034
}

\author{
Edición Extraordinaria. p.p. $44-83$
}

Memorias del IX Encuentro Nacional de Experiencias en Enseñanza de la Biología y la Educación Ambiental. IV Congreso Nacional de Investigación en Enseñanza de la Biología.

intuitivos, creativos y emocionales, Parsons (citado en Efland. 2004) logrando alcanzar esos elementos de valoración y cuidado hacia la biodiversidad.

Sin dejar de lado, la importancia que ha tenido la ilustración científica en el estudio de la biología, usada en claves taxonómicas para identificación de especies e incluso para registrar los hallazgos de expediciones de flora y fauna (Blanco y Gaido, 2013), pero que se ha dejado de emplear, por el uso de nuevas tecnologías, sin embargo esta sigue siendo la estrategia más funcional, no solo por la facilidad de conseguir materiales, sino también, por las características tan específicas de los organismos que se logran destacar y la capacidad de síntesis de información, tiempo y espacio en una sola imagen (Fonseca, M. 2012) y en especial, por la experiencia que puede ser obtenida por medio de los sentidos ofreciendo modos únicos de representar ideas y sentimientos (Efland, 2004)

Complementando esta idea de ilustración científica, se emplearon los insectos, que gracias a su gran diversidad (solo en Colombia se han registrado más de 20.000 especies Global Biodiversity Information Facility (GBIF) (Citado en Sistema Integrado de Biodiversidad Colombia (SIB Colombia, 2016)), abundancia, complejidad morfológica y ecológica, se pueden encontrar con gran facilidad en contextos urbanos y rurales, por estas características y por su facilidad de manejo en la escuela (Rodríguez y Escobar 2013) se convierten en los organismos ideales para ilustrar, y para conocer los valores y cuidados asociados a la biodiversidad.

Los valores que aquí se mencionan hacen referencia a los valores intrínsecos de la naturaleza en sí misma, independientes de cualquier utilidad para los seres humanos, entendiendo que todo en la naturaleza posee su propio y absoluto derecho de existir (Torres, 2012); Los valores instrumentales, no como una valorización de mercado, sí no como un componente de la naturaleza que brinda una función para la sociedad, incluyendo los servicios ecológicos; por último, los valores emocionales, que contribuyen al bienestar emocional, espiritual y estético de los seres humanos, pueden originarse en la identificación y el cuidado de los sistemas ecológicos (Trombulak et al. 2004).

De igual forma, este proyecto pretende contribuir a las estrategias pedagógicas para la conservación, concepto que se han venido desarrollado los últimos años por la urgencia brindar educación contextual y que las personas adquieran conciencia de su entorno y puedan realizar cambios en sus valores, conductas y estilos de vida, para lograr un medio ambiente en equilibrio (Melo, 2013), además de ser necesario en Colombia, por la urgencia de reflexionar sobre el actuar del Licenciado en Biología frente a las problemáticas de la biodiversidad del entorno, dando uso a espacios urbanos de enseñanza como la huerta escolar (Rodríguez y Escobar, 2013) y llegar a una complementación con las reflexiones de los estudiantes del curso 804 y maestros de biología y artes de la institución CEDID Ciudad Bolívar.

\section{MATERIALES Y MÉTODOS}

Este trabajo se está orientando bajo la metodología Investigación- Acción, que supone 
Bio - grafía. Escritos sobre la Biología y su Enseñanza. ISSN 2027-1034

Edición Extraordinaria. p.p. 44 - 83

Memorias del IX Encuentro Nacional de Experiencias en Enseñanza de la Biología y la Educación Ambiental. IV Congreso Nacional de Investigación en Enseñanza de la Biología.

una amplia gama de estrategias realizadas para mejorar el sistema educativo y social. Se entiende, además, como una reflexión que tiene como objetivo ampliar la comprensión de los docentes sobre sus problemas prácticos. Las acciones van encaminadas a modificar la situación una vez que se logre una comprensión más profunda de los problemas, en otras palabras se establece una espiral introspectiva donde se Planifica, Actúa, Observa y Reflexiona. (Elliott, 1993)

Esta espiral introspectiva se hace evidente en el proyecto al momento de formular las sesiones y actividades, que además, están guiadas por el modelo pedagógico Enseñanza para la Comprensión (EpC), definido por Perkins (2005), como una visión de la educación y propuesta de desempeños que apela a una variedad de metodologías para alcanzar la comprensión, entendiendo esta última como la habilidad de pensar y actuar de manera flexible con lo que se sabe. Para lograr este cometido, Perkins plantea los siguientes parámetros en la EpC:

- Todos los trabajos que se desarrollen desde la EpC deben tener como fin un proyecto síntesis, entendido como un proyecto integrador que se desarrolla durante el tiempo establecido, y bajo el cual se deben planear cada una de las actividades y sesiones, buscando siempre aportar al mismo, son de gran importancia para la evaluación diagnóstica y continua demostrando claramente lo que cada estudiante llegó a comprender. En esa evaluación se tendrán en cuenta las diferentes dimensiones de comprensión como son los contenidos, también llamados cuerpos de conocimiento, considerados como herramientas de reflexión que permiten resolver problemas, formular juicios, contar historias y transformar la cotidianidad, los métodos que serían el cómo se construye el conocimiento, busca fomentar una actitud escéptica acerca de lo que conoce o escucha, los propósitos que buscan tener en cuenta las convicciones de los estudiantes para investigar algo y las maneras de aplicar el conocimiento para resolver los problemas que conllevan a investigar, y finalmente las formas de comunicación, donde el estudiante desarrolla habilidades y destrezas en la recolección, sistematización, clasificación y socialización de información, explicando de manera consistente los contenidos, métodos y propósitos del tema estudiado.

- También establece cuatro Niveles de comprensión: Ingenuo, Principiante, Aprendiz y Maestría, bajo los cuales se evalúa cada estudiante dependiendo del nivel de comprensión que logró con su proyecto, donde el nivel ingenuo sería la comprensión más básica y se irá escalando hasta el nivel más alto de comprensión: Maestría.

- Los cronogramas de sesiones se deben establecer de forma clara tanto para el maestro como para el estudiante, estructurados bajo cuatro pilares: los hilos conductores, o preguntas amplias que guían el trabajo durante todas las sesiones, los tópicos generativos, que son los temas que se han pensado para aportar a la realización del proyecto, que responden a la pregunta ¿qué debemos enseñar?, los desempeños de comprensión o la descripción clara de cómo se abordarán cada uno de los tópicos planteados, y finalmente las metas de 
Bio - grafía. Escritos sobre la Biología y su Enseñanza. ISSN 2027-1034

Edición Extraordinaria. p.p. 44 - 83

Memorias del IX Encuentro Nacional de Experiencias en Enseñanza de la Biología y la Educación Ambiental. IV Congreso Nacional de Investigación en Enseñanza de la Biología.

comprensión que son el horizonte hacia el cual se quiere guiar al estudiante o alcances a los que quieren que sus estudiantes accedan.

En esta investigación el proyecto síntesis será la bitácora de ilustraciones científicas, que permitirá evaluar el nivel de comprensión que los estudiantes han logrado alcanzar sobre la valoración y cuidado de la biodiversidad, además de evidenciar los procesos de metacognición, para abarcar las dimensiones de comprensión, se construyeron junto con los maestros de biología y artes de la institución unas rúbricas que evalúan las dimensiones de Contenidos y Formas de Comunicar, porque estas pueden abarcar de manera general el proyecto, sin excluir las otras dos dimensiones, las cuales se evalúa de forma indirecta.

\begin{tabular}{|l|l|}
\hline \multicolumn{1}{|c|}{ Fase } & \multicolumn{1}{c|}{ Actividades realizadas y por realizar } \\
\hline Contextualización & Con ayuda de revisiones documentales se realizaron \\
& acercamientos a la localidad Ciudad Bolívar y al barrio \\
& Sierra Morena, y por medio de visitas periódicas al \\
& Colegio CEDID Ciudad Bolívar se caracterizaron las \\
& zonas verdes allí presentes. \\
- Se buscó y eligió el grupo focal, por cuestión de tiempo & y espacio el grupo 804 jornada mañana fue \\
& seleccionado. \\
& Con ayuda de entrevistas semiestructuradas realizadas \\
& a los profesores de artes y biología de la institución se \\
& evidencia cual es el trabajo que se ha realizado sobre \\
biodiversidad en la institución.
\end{tabular}


Bio - grafía. Escritos sobre la Biología y su Enseñanza. ISSN 2027-1034

Edición Extraordinaria. p.p. 44 - 83

Memorias del IX Encuentro Nacional de Experiencias en Enseñanza de la Biología y la

Educación Ambiental. IV Congreso Nacional de Investigación en Enseñanza de la Biología.

\begin{tabular}{|l|l|}
\hline & $\begin{array}{l}\text { actividades base (Ver Anexo 1), el cual se fue } \\
\text { adecuando y reestructurando de acuerdo con las } \\
\text { necesidades que iban siendo evidentes en los } \\
\text { cuadernos de campo de los estudiantes, llegando a } \\
\text { conformar un cronograma final (Ver Anexo 4) adecuado } \\
\text { a la población. }\end{array}$ \\
\hline $\begin{array}{l}\text { Aplicación de la estrategia } \\
\text { pedagógica }\end{array}$ & $\begin{array}{l}\text { Se desarrollan trabajos prácticos en la huerta y laboratorio, } \\
\text { consultas teóricas, recolección e identificación de insectos, y } \\
\text { conocimiento y aplicación de las técnicas de ilustración, } \\
\text { elaborando como proyecto síntesis la bitácora de ilustraciones } \\
\text { científicas de insectos. (Con más detalle en Anexo 4) }\end{array}$ \\
\hline $\begin{array}{l}\text { Evaluación diagnóstica y } \\
\text { continua }\end{array}$ & $\begin{array}{l}\text { Para evaluar la pertinencia del proyecto en la comprensión de } \\
\text { los estudiantes se aplicaran nuevamente rúbricas de } \\
\text { evaluación. }\end{array}$ \\
\hline $\begin{array}{l}\text { Evaluación diagnóstica y } \\
\text { continua del maestro en } \\
\text { formación }\end{array}$ & $\begin{array}{l}\text { Los estudiantes del curso 804, y los maestros de biología y } \\
\text { artes realizaran la evaluación del maestro en formación por } \\
\text { medio de una rúbrica de evaluación (Ver Anexo 5) para aportar } \\
\text { a su práctica. }\end{array}$ \\
\hline
\end{tabular}

En este orden de ideas, para responder a las espirales introspectivas de la investigaciónacción y los parámetros de la EpC, se planificó un cronograma de sesiones base (Ver anexo 1), luego se aplicó la primera actividad, se observó la acción del estudiante y sus progresos, que se hicieron evidentes en el cuaderno de campo que llevan, y se reflexionó con los maestros de biología y artes de la institución, permitiendo reestructurar las actividades propuestas en el cronograma, estos pasos se realizaron en cada una de las sesiones.

Para evidenciar y reflexionar sobre el cómo los estudiantes y el maestro están avanzando hacia los desempeños de comprensión se diseñaron e implementaron unas rúbricas de evaluación, en las que se desarrollaron procesos de Autoevaluación, heteroevaluación y coevaluación, ejercicio fundamental para que el estudiante reconozca sus avances y se rete a mejorar, de la misma manera para que el maestro en formación reflexione sobre su quehacer, aportando a su desarrollo como profesional.

Así, el proyecto se desarrolla en las siguientes fases:

\section{RESULT ADOS Y DISCUSIONES (PARCIALES)}

Aquí se presentan los resultados parciales de este proyecto investigativo, se espera que el proyecto tenga finalidad en el mes de junio del presente año. 
Bio - grafía. Escritos sobre la Biología y su Enseñanza. ISSN 2027-1034

Edición Extraordinaria. p.p. 44 - 83

Memorias del IX Encuentro Nacional de Experiencias en Enseñanza de la Biología y la Educación Ambiental. IV Congreso Nacional de Investigación en Enseñanza de la Biología.

\section{Fase 1: Contextualización}

Partiendo de la revisión documental, se puede afirmar que la localidad de Ciudad Bolívar ha sido configurada a partir de procesos de invasión y dos etapas de urbanización muy marcadas. La localidad de Ciudad Bolívar al estar ubicada en los cerros bordes de la Ciudad de Bogotá se consideraba uno de los sitios con mayor biodiversidad de flora y fauna de la ciudad, el cual se ha venido deteriorando los últimos 60 años por la instauración de ladrilleras y los asentamientos subnormales de campesinos desplazados, producto de los conflictos internos del país. (Alcaldía Local Ciudad Bolívar, 2013).

Estos asentamientos dieron lugar a 8 UPZ en la parte urbana, entre ellas la UPZ 69 Ismael Perdomo, que Según la Cartilla pedagógica del Plan de Ordenamiento Territorial (POT) de la alcaldía mayor de Bogotá (2007) posee 65 barrios de estratos 1 y 2 . En ésta UPZ, podemos encontrar el barrio Sierra Morena, en él se ubica el colegio CEDID Ciudad Bolívar; un colegio grande, de estructura contemporánea construido en 1987. (CEDID Ciudad Bolívar, 2011)

Los profesores de la institución han venido desarrollando proyectos que involucran el uso de las zonas verdes desde hace más de 10 años, uno de los proyectos que más tuvo relevancia fue la construcción de un espacio para realizar cultivo urbano, denominado "huerta escolar un proyecto de vida", en él se involucraron profesores de biología, artes, educación física y humanidades, sin embargo, al paso de los años este espacio dejo de ser usado para la implementación de estrategias educativas, razón por la cual actualmente se encuentra en fase de reconformación, esta información fue obtenida gracias a la entrevista semiestructurada realizada a dos profesores de la institución, Miller Rodríguez del componente de biología y Saúl Ramírez de artes. Por iniciativa de los profesores y con el ánimo de desarrollar la práctica pedagógica, se eligió el curso 804 para retomar las actividades en la huerta, además de establecer un proyecto interdisciplinar capaz de reunir los conocimientos de artes y biología en una estrategia pedagógica que pueda ser modificada y aplicada con posterioridad. Gracias a la encuesta (Anexo 2) se encontró que el curso 804 está conformado por 40 estudiantes, entre los 12 y 16 años, de los cuales 17 son hombres y 23 son mujeres.

\section{Fase 2: Acción participante.}

Resultados de la encuesta realizada en el mes de julio de 2016, ver con más detalle en el Anexo 2:

\begin{tabular}{|l|l|}
\hline \multicolumn{1}{|c|}{ Pregunta } & \multicolumn{1}{c|}{ Respuestas } \\
\hline $\begin{array}{l}1 . \text { ¿Cuáles zonas verdes identifica } \\
\text { usted en su escuela? }\end{array}$ & $\begin{array}{l}\text { Un de los estudiantes reconocen la huerta del colegio como una zona } \\
\text { verde, un 70\% establecen otras zonas verdes como el jardín, el patio de } \\
\text { primera infancia y la cancha de futbol (teniendo en cuenta que se podía hacer } \\
\text { selección múltiple), con lo que se deduce que los estudiantes tienen una } \\
\text { comprensión sobre las zonas verdes como espacios con vegetación, } \\
\text { especialmente pastizales donde organismos presentan interacciones. }\end{array}$ \\
\hline 2. ¿Tiene usted acceso o contacto Un $60 \%$ de la población asegura tener un contacto directo con dichas zonas
\end{tabular}




\title{
Bio - grafía. Escritos sobre la Biología y su Enseñanza. ISSN 2027-1034
}

\author{
Edición Extraordinaria. p.p. 44 - 83
}

\section{Memorias del IX Encuentro Nacional de Experiencias en Enseñanza de la Biología y la Educación Ambiental. IV Congreso Nacional de Investigación en Enseñanza de la Biología.}

\begin{tabular}{|c|c|}
\hline recto con estas zonas verdes? & $\begin{array}{l}\text { verdes, especialmente en la hora del descanso, otro } 40 \% \text { aseguran haber } \\
\text { usado la huerta en clases de biología, en proyectos realizados cor } \\
\text { anterioridad en el año } 2015 \text { e inicios del } 2016 \text { por el profesor Miller Rodríguez, } \\
\text { en el que trabajaron conceptos de ecología y redes tróficas con algunos } \\
\text { estudiantes del curso, muchos de ellos no realizaron estas actividades porque } \\
\text { no pertenecían al curso o incluso a la institución. }\end{array}$ \\
\hline $\begin{array}{l}\text { 3. ¿Qué clase de act } \\
\text { realizado en estos esp } \\
\text { sido de su agrado? }\end{array}$ & $\begin{array}{l}\text { El } 40 \% \text { de la población ha realizado cultivo urbano en años anteriores, o } \\
60 \% \text { usa estos espacios para ocio, para realizar deportes y actividades } \\
\text { relajación. Todas estas actividades han sido de su agrado. Se puede dedu } \\
\text { que los estudiantes disfrutan del acercamiento a estas zonas verdes. }\end{array}$ \\
\hline - ¿Qué clase de actividades & $\begin{array}{l}\text { El } 60 \% \text { de la población le gustaría realizar la clase de biología en la huer } \\
\text { también seguir con sus cultivos urbanos, un } 5 \% \text { de la población le gusta } \\
\text { conocer los organismos presentes, y otro } 55 \% \text { le gustaría seguir realizan } \\
\text { actividades de ocio y relajación en estos espacios. Se hace evidente } \\
\text { urgencia de volver a emplear estos espacios para la realización de las clas } \\
\text { de biología, y que los estudiantes tienen la disposición de participar } \\
\text { actividades que involucren el conocimiento de los organismos que allí } \\
\text { encuentran. }\end{array}$ \\
\hline
\end{tabular}

5. ¿Practica o le llaman la atención Entre las expresiones artísticas que más le llama la atención a los estudiantes alguna de las siguientes se encuentra con un $60 \%$ la música, con un $53 \%$ el dibujo y un $10 \%$ el grafiti, expresiones artísticas? (puede más de la mitad de la población muestra afinidad con el dibujo, siendo una marcar más de una): Grafiti, Dibujo, muestra representativa que reivindica el uso de la ilustración en la enseñanza Música, Pintura, Literatura, Otra, de la biología.

¿Cuál?

6. Describa las que usted considereEn esta pregunta, los estudiantes muestran un manejo conceptual amplio características propias de lossobre los insectos, algunos reconocen que estos posen 6 patas, antenas y insectos

hacen relaciones de tamaño y forma, sin embargo, se presentan confusiones con otros invertebrados como arañas, cien pies, cochinillas, gusanos lombrices.

7. ¿Qué insectos conoce? Y ¿En Los estudiantes establecen relaciones zona verde- insecto. dónde los ha visto?

8. Realice un dibujo de alguno de Las relaciones de tamaño y forma están muy bien empleadas, se evidencia la los insectos que conozca. confusión entre insectos y otros invertebrados, algunos representan interacción insecto- planta.

9. Para usted que es la Un $40 \%$ de la población desconoce el concepto, por lo que se abstuvieron de biodiversidad $\quad$ responder, el otro $60 \%$ reconoce la biodiversidad como la cantidad de animales y plantas que hay en el mundo.

10. Considera que se debe cuidar y Entre el $40 \%$ de los estudiantes que respondieron, el $100 \%$ asegura que es valorar la biodiversidad ¿Por qué? fundamental cuidar esta biodiversidad porque estos organismos sor importantes para el mundo, sin embargo, no se profundiza en el por qué.

Resultados parciales de las rubricas de evaluación realizadas con los profesores de Artes y Biología, aplicadas a los estudiantes del curso 804 (Autoevaluación) para evidenciar los conocimientos previos, se debe tener en cuenta el Anexo 2 para los descriptores de cada 
Bio - grafía. Escritos sobre la Biología y su Enseñanza. ISSN 2027-1034

Edición Extraordinaria. p.p. 44 - 83

Memorias del IX Encuentro Nacional de Experiencias en Enseñanza de la Biología y la

Educación Ambiental. IV Congreso Nacional de Investigación en Enseñanza de la Biología.

nivel de comprensión.

\begin{tabular}{|c|c|c|}
\hline $\begin{array}{l}\text { Dimensión de } \\
\text { comprensión }\end{array}$ & Hilo conductor & Resultados \\
\hline \multirow[t]{6}{*}{ Contenidos } & $\begin{array}{l}\text { ¿Cuáles son las interacciones que se presentan en } \\
\text { las zonas verdes de mi colegio? }\end{array}$ & $\begin{array}{l}7 \text { estudiantes se autoevalúan en el nivel de } \\
\text { comprensión maestría, } 16 \text { en aprendiz, } 10 \text { en } \\
\text { principiante y } 7 \text { en ingenuo. }\end{array}$ \\
\hline & $\begin{array}{l}\text { ¿Cuáles son las características propias de los } \\
\text { insectos? ¿Qué los diferencia de otros } \\
\text { invertebrados? }\end{array}$ & $\begin{array}{l}\text { Se encuentra que } 3 \text { estudiantes se evalúan } \\
\text { en el nivel de maestría, } 17 \text { en aprendiz, } 11 \text { en } \\
\text { principiante y } 9 \text { en ingenuo. }\end{array}$ \\
\hline & $\begin{array}{l}\text { ¿Cómo puedo conocer los insectos presentes en la } \\
\text { huerta de mi colegio? } \\
\text { ¿Cuáles son los insectos que hay en la huerta de } \\
\text { mi colegio? }\end{array}$ & $\begin{array}{|llll|}\text { en maestría, } 5 \text { en aprendiz, } 20 & \text { en } \\
\text { principiante y } 14 \text { en ingenuo } & \\
2 \text { en maestría, } 10 \text { en aprendiz, } 14 & \text { en } \\
\text { principiante y } 14 \text { en ingenuo }\end{array}$ \\
\hline & $\begin{array}{l}\text { ¿Cómo perciben y responden los insectos a los } \\
\text { estímulos de su medio? } \\
\text { ¿Qué importancia tienen los insectos en la huerta } \\
\text { en el mundo? }\end{array}$ & $\begin{array}{l}3 \text { en maestría, } 3 \text { en aprendiz, } 27 \\
\text { principiante y } 7 \text { en ingenuo } \\
15 \text { en maestría, } 17 \text { en aprendiz, } 7 \\
\text { principiante y } 1 \text { en ingenuo }\end{array}$ \\
\hline & $\begin{array}{l}\text { ¿Cómo y por qué se deben valorar y cuidar los } \\
\text { insectos presentes en la huerta del colegio? }\end{array}$ & $\begin{array}{l}24 \text { en maestría, } 7 \text { en aprendiz, } \\
\text { principiante y } 5 \text { en ingenuo }\end{array}$ \\
\hline & $\begin{array}{l}\text { ¿Cuál es la diferencia entre un dibujo y una } \\
\text { ilustración? y ¿Cuáles son las técnicas de } \\
\text { ilustración y cómo puedo emplearlas? }\end{array}$ & $\begin{array}{l}2 \text { en maestría, } 10 \text { en aprendiz, } 20 \text { en } \\
\text { principiante y } 8 \text { en ingenuo }\end{array}$ \\
\hline $\begin{array}{l}\text { ormas } \\
\text { omunicar }\end{array}$ & $\begin{array}{l}\text { ¿Cómo represento las situaciones cotidianas } 1 \\
\text { que percibo en mi entorno? }\end{array}$ & $\begin{array}{l}17 \text { en maestría, } 20 \text { en a } \\
\text { principiante }\end{array}$ \\
\hline
\end{tabular}

Los resultados generales muestran que el $20,5 \%$ de la población se sitúa en el nivel de maestría, el $79,5 \%$ restante se autoevalúan en niveles de aprendiz, principiante e ingenuo, se espera que este proyecto permita que los estudiantes se reten a mejorar y puedan alcanzar y superar los niveles de comprensión establecidos y pensados según los estándares para dicho curso, además, estos descriptores fueron realizados con los maestros de biología y artes de la institución, sin dejar de lado el currículo de los mismos.

Fase 3: Planteamiento de actividades

Teniendo la información de las fases anteriores, se propuso un cronograma de actividades base (Ver Anexo 1), que fue adecuado y reestructurado con ayuda de los maestros de biología y artes, las actividades se iban enlazando, buscando una correlación entre las mismas, ninguna actividad era planeada sin tener en cuenta la anterior, además de escuchar las necesidades de los estudiantes, que iban siendo evidentes en los cuadernos de campo de los mismos, quienes lo diligenciaban en cada sesión, expresando los gustos e intereses que tenían para que pudieran desarrollarse durante las sesiones posteriores, esta espiral introspectiva (Gráfica 1) llego a conformar un cronograma final (Ver Anexo 4). 
Bio - grafía. Escritos sobre la Biología y su Enseñanza. ISSN 2027-1034

Edición Extraordinaria. p.p. 44 - 83

Memorias del IX Encuentro Nacional de Experiencias en Enseñanza de la Biología y la Educación Ambiental. IV Congreso Nacional de Investigación en Enseñanza de la Biología.

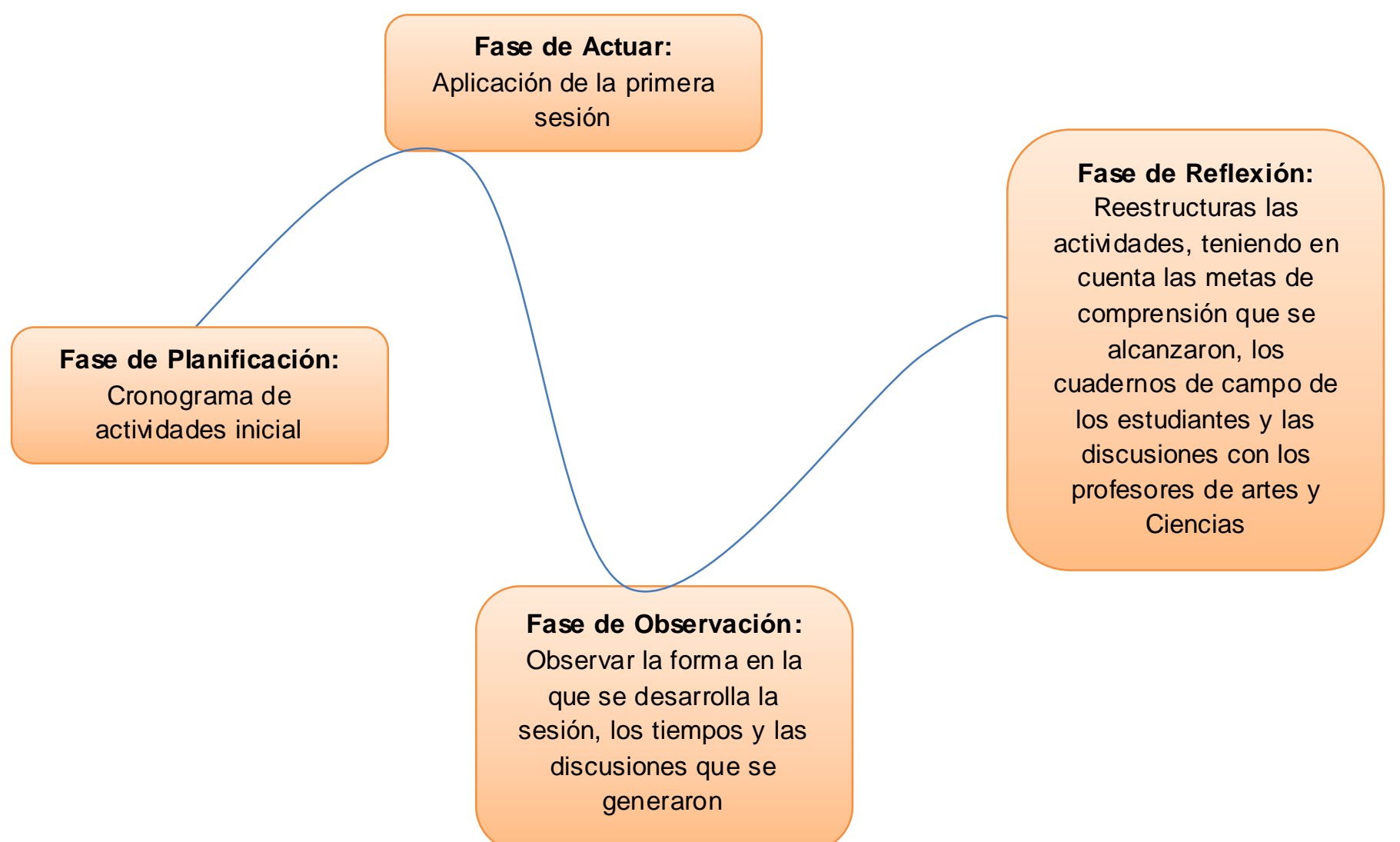

Gráfica 1: Bucles de retroalimentación o espiral introspectiva realizada en cada sesión, teniendo en cuenta la EpC y la investigación- acción.

\section{Fase 4: Aplicación de la estrategia}

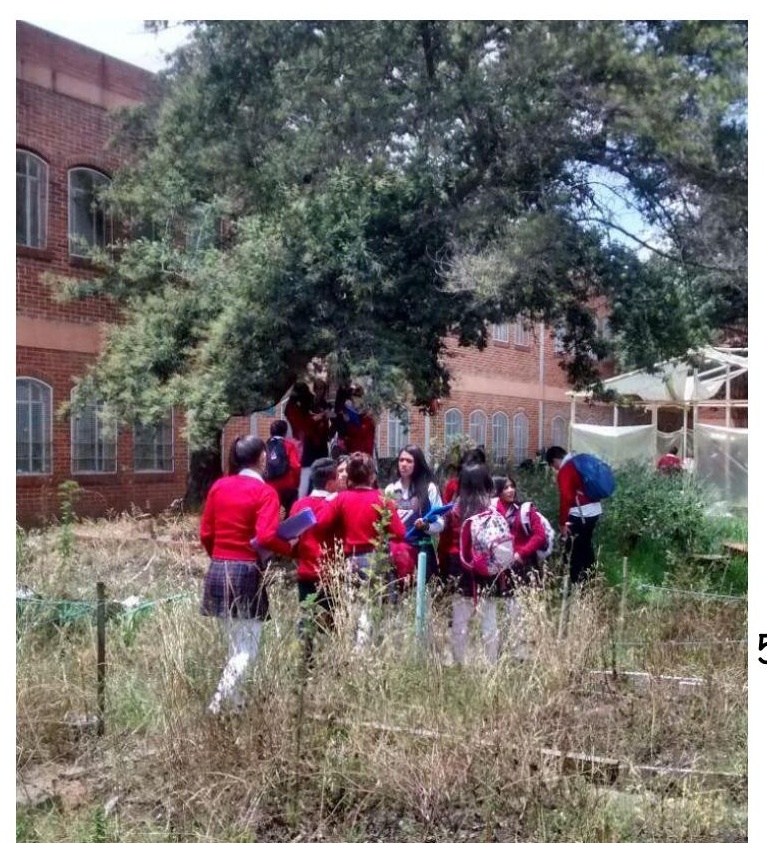

\section{Sesión 1:}

Hilo conductor: ¿Cuáles son las interacciones que se presentan en las zonas verdes de mi colegio?

Los estudiantes tuvieron un acercamiento a las zonas verdes de su colegio, específicamente a la huerta, reconociéndola como parte de su territorio y como un lugar de interacción de diferentes organismos, en especial de los insectos, reconociéndolos como la otredad, es decir como organismos 


\section{Bio - grafía. Escritos sobre la Biología y su Enseñanza. ISSN 2027-1034}

Edición Extraordinaria. p.p. 44 - 83

Memorias del IX Encuentro Nacional de Experiencias en Enseñanza de la Biología y la Educación Ambiental. IV Congreso Nacional de Investigación en Enseñanza de la Biología.

vivos, que interactúan y necesitan de un espacio para vivir.

Realizaron un primer ejercicio de ilustración, donde debían representar al insecto que más llamara su atención, esto con el fin de conocer las ideas previas sobre lo que ellos consideran es un insecto y sus nociones básicas de ilustración.

El resultado de esta primera ilustración permitirá un ejercicio de Autoevaluación y Metacognición, donde el estudiante podrá evidenciar el progreso que tuvo durante las diferentes sesiones.

\section{Sesión 2:}

Hilo conductor: ¿Cuáles son las características propias de los insectos? ¿Qué los diferencia de otros invertebrados?

Luego de realizar la primera intervención es evidente que los estudiantes tienen confusiones sobre lo que es un insecto o un artrópodo, por lo que se hace necesario conocer la clasificación de los invertebrados, y de los Phylum que conforman este grupo, haciendo énfasis en las clases de artrópoda, para determinar las características específicas de un insecto.

Esta clasificación se construyó con ayuda de los estudiantes quienes aportando sus conocimientos previos permitieron conformar un mapa conceptual y de esta manera confrontar las ideas previas de los estudiantes sobre los insectos, comprendiendo qué es un artrópodo, qué lo caracteriza y cómo poder diferenciarlo.

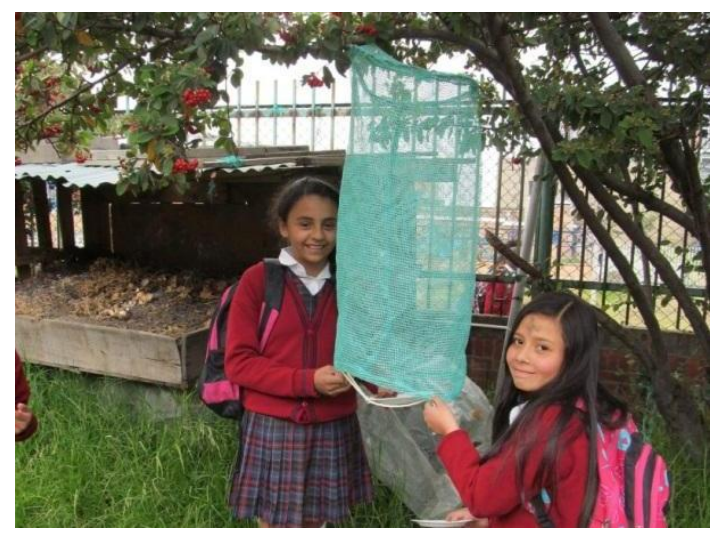

Sesión 3, 4, 5, 6: ¿Cómo puedo conocer la biodiversidad de insectos presentes en la huerta de mi colegio?, ¿Son las trampas la mejor opción para conocer los insectos de la huerta?

Los estudiantes conocen las diferentes trampas de captura de insectos y como estas pueden ser un instrumento viable para el conocimiento de la biodiversidad de su huerta, para evitar el sacrificio, se tomaron fotografías que permitieron determinar hasta orden los organismos, cada estudiante escogió un insecto, el que más tuviera afinidad y el que más llamara su atención, luego cada estudiante debía clasificar y describir su insecto, para evidenciar si se aplica o no los conceptos vistos en clase. 
Bio - grafía. Escritos sobre la Biología y su Enseñanza. ISSN 2027-1034

Edición Extraordinaria. p.p. 44 - 83

Memorias del IX Encuentro Nacional de Experiencias en Enseñanza de la Biología y la Educación Ambiental. IV Congreso Nacional de Investigación en Enseñanza de la Biología.
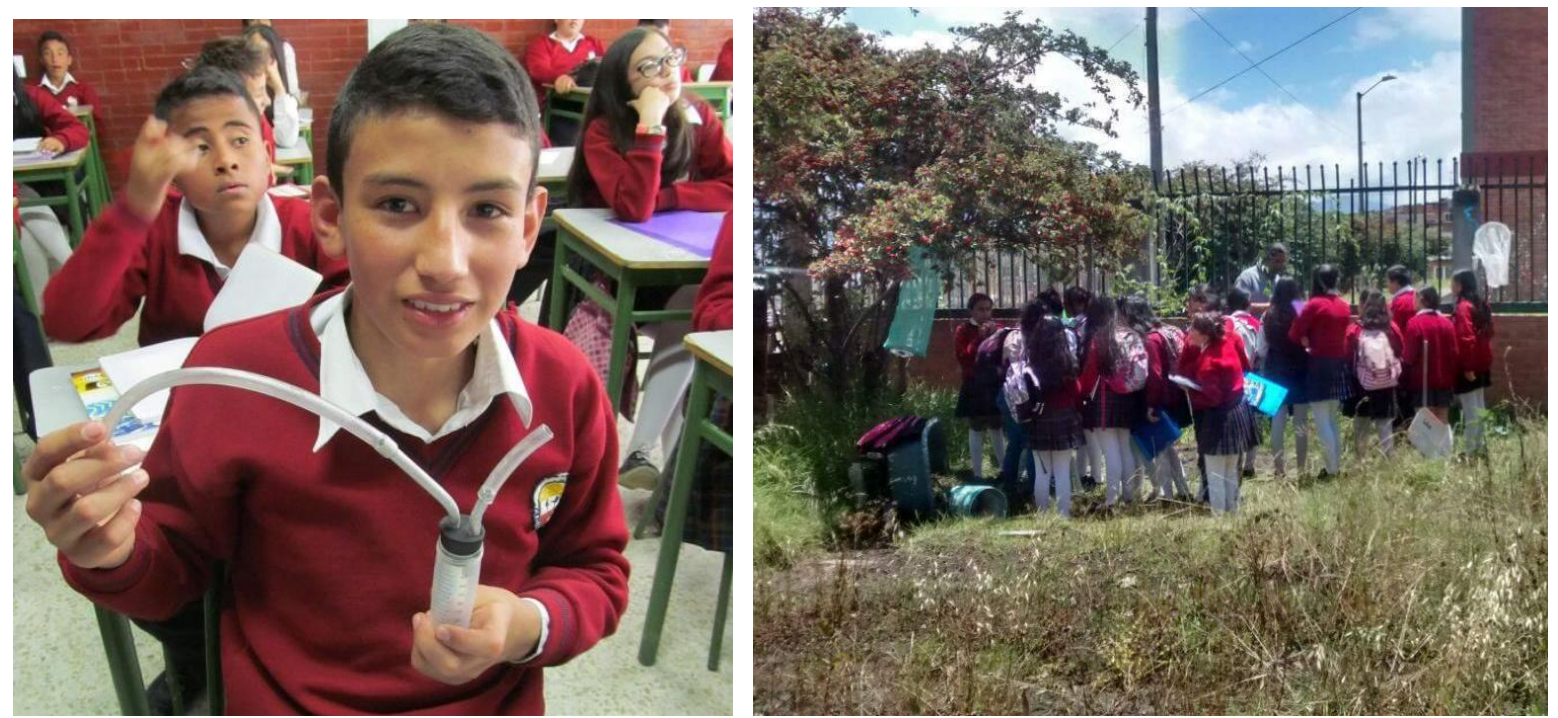

\section{Sesión 7:}

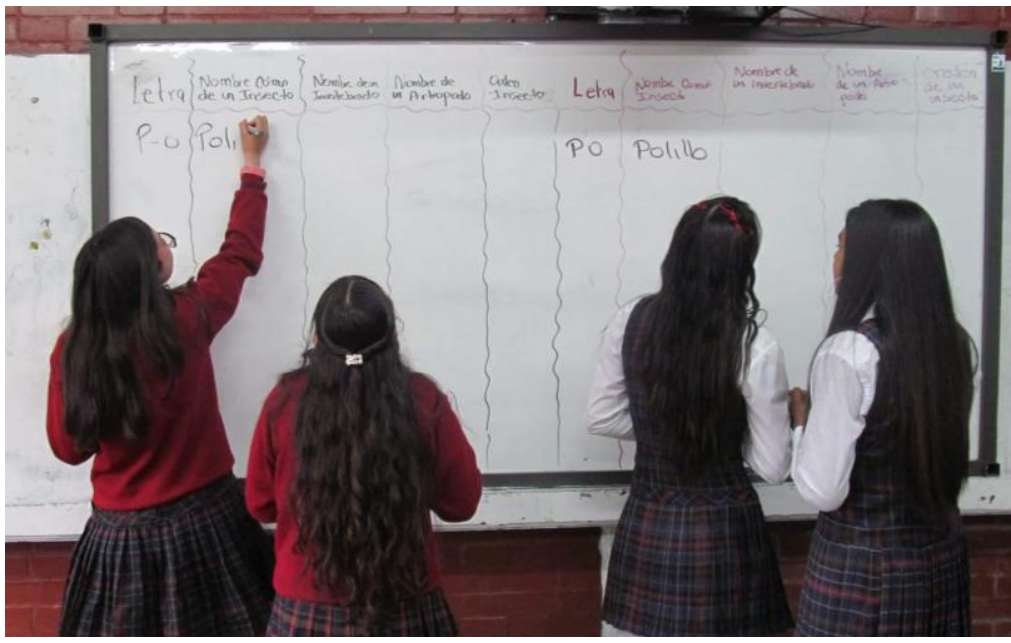

Hilo conductor: ¿Cómo y qué he aprendido hasta ahora?

Se realizó una evaluación que permitió que el profesor evidenciara que han aprendido sus estudiantes, en qué temas se tienen falencias y que se debe reforzar.

Ésta fue a manera de Stop, y los estudiantes pudieron evidenciar que tanto han aprendido, su dominio de conceptos y su manejo de problemáticas cotidianas, permitiendo una retroalimentación al profesor.

También, se puso en práctica la autoevaluación y la coevaluación, criterios importantes para evidenciar su nivel de comprensión.

\section{Sesión 10:}

Hilo conductor: ¿Qué es la ilustración científica y como puedo emplearla para representar mi insecto? 
Bio - grafía. Escritos sobre la Biología y su Enseñanza. ISSN 2027-1034

Edición Extraordinaria. p.p. 44 - 83

Memorias del IX Encuentro Nacional de Experiencias en Enseñanza de la Biología y la Educación Ambiental. IV Congreso Nacional de Investigación en Enseñanza de la Biología.

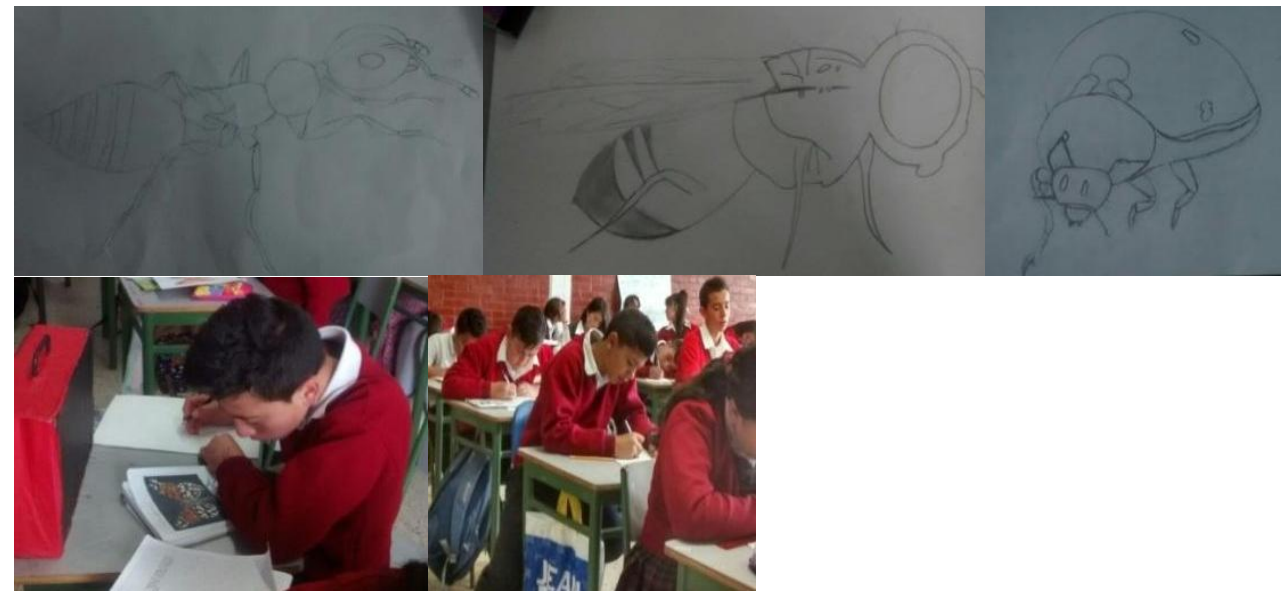

Breve reseña histórica sobre la ilustración científica y la importancia en la biología. Se practicó la bocetación, teniendo como guía las fotografías tomadas en la huerta, o en su defecto imágenes tomadas de internet, se realizó la primera ilustración en grafito del insecto.

\section{Sesión 11:}

Hilo conductor: ¿Cómo perciben y responden los insectos a los estímulos de su medio? ¿Tienen los insectos súper sentidos?

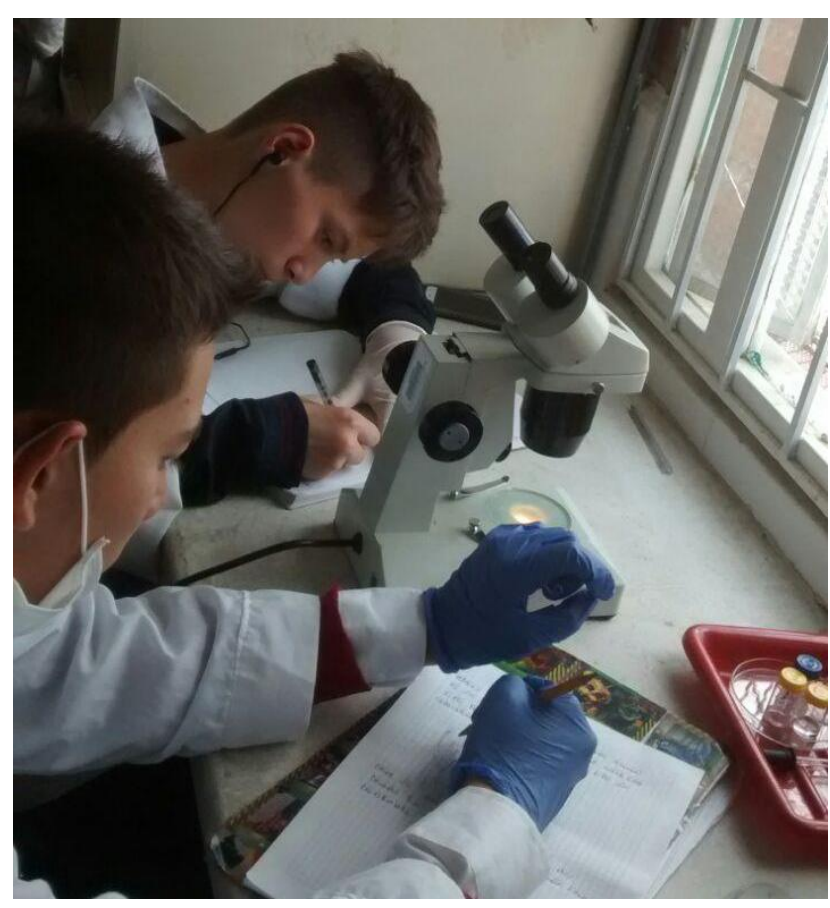

Los estudiantes desarrollaron habilidades científicas en el laboratorio, como son la observación, el análisis, la deducción y la resolución de problemáticas, asociadas a la morfo fisiología de los insectos, específicamente a los sentidos.

También, comprenden como los insectos interactúan con el medio y las similitudes que pueden encontrarse entre los sentidos de los insectos y de los mamíferos

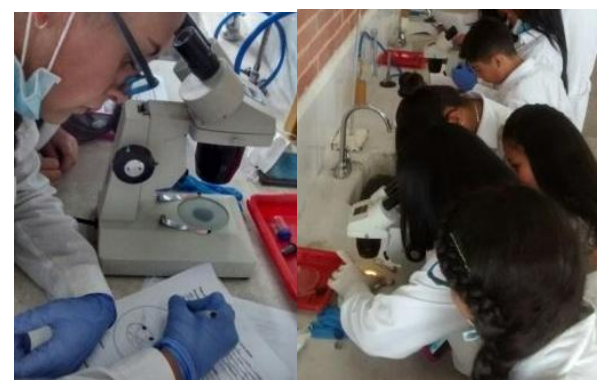


Bio - grafía. Escritos sobre la Biología y su Enseñanza. ISSN 2027-1034

Edición Extraordinaria. p.p. 44 - 83

Memorias del IX Encuentro Nacional de Experiencias en Enseñanza de la Biología y la Educación Ambiental. IV Congreso Nacional de Investigación en Enseñanza de la Biología.

\section{Sesión 12:}

Hilo conductor: ¿Cómo puedo emplear el puntillismo para representar las estructuras sensoriales de los insectos?

Teniendo como base el laboratorio realizado donde se observaron las estructuras sensoriales de los insectos, la construcción de estos conocimientos serán recopilados en una ilustración científica, donde por medio de puntos van a representar estas estructuras, llegando a conocerlas a detalle e interactuando íntimamente con cada parte del insecto.

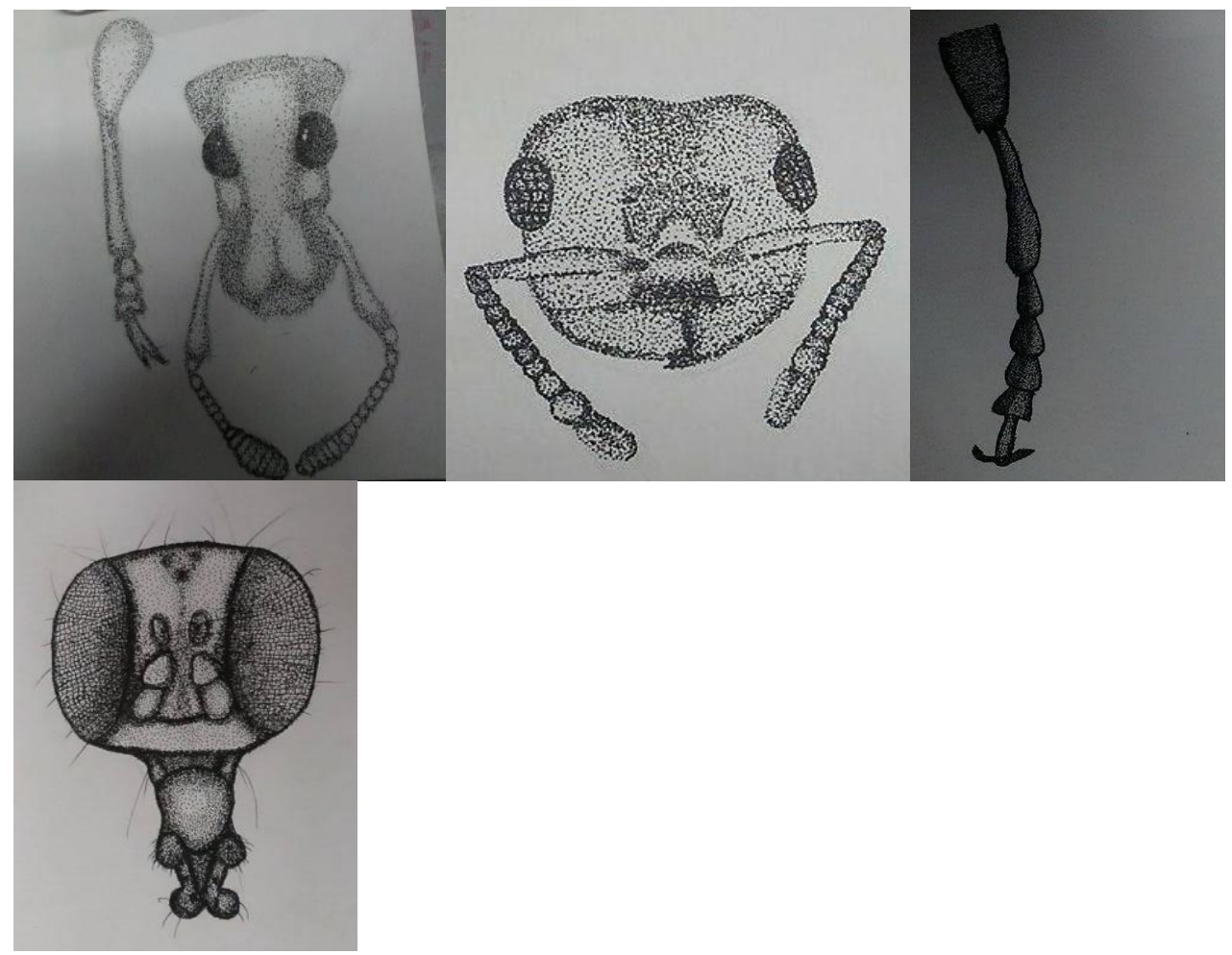

Este trabajo de ilustración permitió que los estudiantes miraran de otra manera los insectos, conociendo estructuras específicas, entendiendo la forma de alimentación, comunicación y relación con el ambiente.

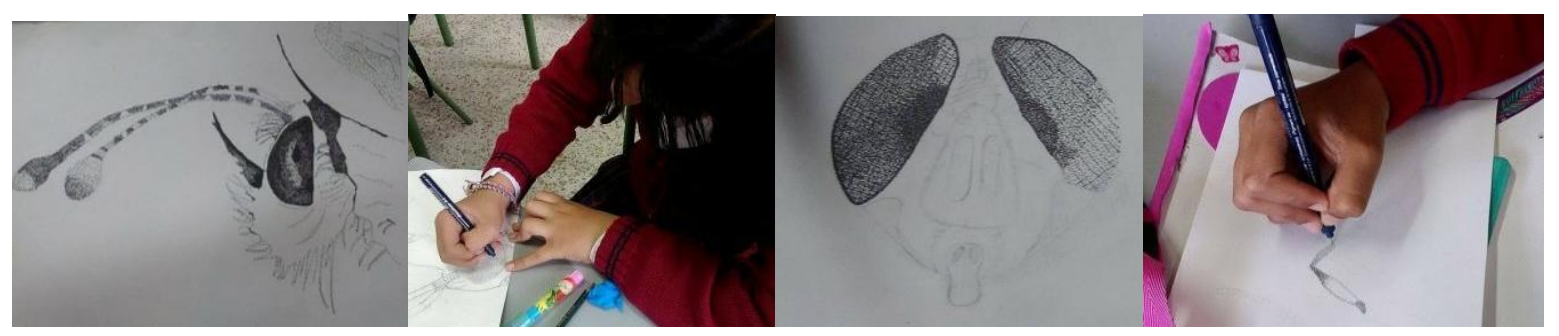

(Las sesiones se describen con más detalle en el Anexo 4). 
Bio - grafía. Escritos sobre la Biología y su Enseñanza. ISSN 2027-1034

Edición Extraordinaria. p.p. 44 - 83

Memorias del IX Encuentro Nacional de Experiencias en Enseñanza de la Biología y la Educación Ambiental. IV Congreso Nacional de Investigación en Enseñanza de la Biología.

Por dinámicas propias de la institución y del país en general, aun no se ha dado finalización a la propuesta sin embargo, se espera concluir el proceso en el presente año.

\section{CONCLUSIONES (PARCIALES)}

- que permite procesos de metacognición en los estudiante, permite materializar los conocimientos obtenidos en clases teóricas y prácticas, representa las formas de pensar de los estudiantes, quienes a partir de la ilustración comprende procesos ecológicos y morfo fisiológicos importantes.

- Es una estrategia atractiva, que cautiva a los estudiantes, quienes se ven comprometidos con las actividades a realizar.

- La práctica pedagógica permitió un espacio de reflexión del maestro en formación con la realidad educativa, donde se materializan los conocimientos que se han ido adquiriendo durante toda su formación como profesional.

- Se deben pensar proyectos que puedan restaurar las dinámicas de las instituciones de educación, empleando espacios próximos a los estudiantes, como la huerta escolar, la cual puede ser usada como aula viva para la enseñanza de la biología, buscando siempre la motivación de los estudiantes, y que los mismos reconozcan las problemáticas del contexto y por medio de trabajos prácticos reconozcan la biodiversidad de insectos asociados a su entorno inmediato, y que con este proceso puedan ampliar su comprensión sobre la importancia de valorar y cuidar los mismos.

- Este proyecto permitió que los estudiantes tuvieran un contacto directo con su entorno que reconocieran parte de la biodiversidad de su colegio, que entendieran cómo y porque hay que cuidar los organismos que se encuentran allí, a pesar de que aún no se ha podido realizar la comparación entre los niveles de comprensión antes y después de la intervención, para el maestro en formación es evidente el cambio de perspectiva que han tenido los estudiantes, quienes muestran actitudes de valoración y cuidado hacia su entorno inmediato.

- Tanto los estudiantes, como los maestros de la institución quieren dar continuidad y finalidad al proceso, entendiendo que esta práctica pedagógica permitió retomar las actividades en la huerta, sin dejar de lado, el trabajo que se ha realizado a partir de dos espacios de educación: el arte y la biología, se espera poder continuar con un proyecto interdisciplinar que tenga una cabida más amplia en la institución y que se pueda seguir trabajando con posterioridad.

\section{REFERENCIAS BIBLIOGRÁFICAS}

- Alcaldía Local Ciudad Bolívar. (2013). Ficha técnica Ciudad Bolívar. Recuperado de: http://www.ciudadbolivar.gov.co/

- Alcaldía Mayor de Bogotá D. C (2007). Acuerdos para construir ciudad, cartillas pedagógicas POT. Recuperado de: http://catalogo.urosario.edu.co/cgibin/koha/opac-search.pl?q=se:Cartillas\%20Pedag\%C3\%B3gicas\%20del\%20POT 
Bio - grafía. Escritos sobre la Biología y su Enseñanza. ISSN 2027-1034

Edición Extraordinaria. p.p. 44 - 83

Memorias del IX Encuentro Nacional de Experiencias en Enseñanza de la Biología y la

Educación Ambiental. IV Congreso Nacional de Investigación en Enseñanza de la Biología.

- Blanco, L \& Gaido, V. (2013) ¿Qué es la llustración Científica? Mito: Revista cultural. 42. Recuperado de: http://revistamito.com/que-es-la-ilustracion-cientifica/

- Blas, M. \& Del Hoyo, J. (2013) Entomología cultural y consenvación de la biodiversidad. Los insectos en las Artes Mayores

- Boff, L. (2002). El cuidado esencial: Ética de lo humano compasión por la tierra. Ed: Trotta. S.A. Madrid, España.

- CEDID Ciudad Bolívar. (2011). Agenda estudiantil Colegio CEDID Ciudad Bolívar. Secretaria de Educación

- Consejo Académico de la Universidad Pedagógica Nacional (2013) Reglamento de Práctica Pedagógica del Proyecto Curricular de la Licenciatura en Biología. Acuerdo Número 016 del 2013. Universidad Pedagógica Nacional. Bogotá, Colombia.

- Efland, A. (2004). Arte y cognición: la integración de las artes en el curriculum. Barcelona: Octaedro

- Elliott, J. (1993). El cambio educativo desde la investigación- Acción. Primera edición. Ediciones Morata, S. L. Madrid. España.

- Fonseca, M. (2012). Dibujo científico, un testigo de la biodiversidad. Revista Virtual: Semanario universidad. Recuperado de: http://semanariouniversidad.ucr.cr/suplementos/crisol/dibujo-cientfico-un-testigode-la-biodiversidad/

- Quijano, P. (2011). Diseño de una cartilla sobre biodiversidad integrando el modelo constructivista y la enseñanza para la comprensión. Trabajo de grado. Universidad Nacional De Colombia, Facultad De Ciencias, Maestría En Enseñanza De Las Ciencias Exactas Y Naturales. Bogotá, Colombia.

- Melo, A. (2013). Estrategias pedagógicas para el conocimiento de la consenvación y sostenibilidad ambiental en la corporación educativa del litoral. · 85 . Boletín Virtual-824 ISNN 2266-1536

- Perkins, David. (2005). La enseñanza para la comprensión: Cómo ir de lo salvaje a lo domesticado. Revista Magisterio 14: 10-14.

- Rodríguez, J \& Escobar, G. (2013). "Insectos en el aula": Una estrategia didáctica para la enseñanza-aprendizaje de la biología en el patio de la escuela. Revista: Bio-grafía Escritos sobre la Biología y su Enseñanza. Edición Extra-Ordinaria. $p$ 476 - 485. Memorias del VII Encuentro Nacional de Experiencias en la Enseñanza de la Biología y la Educación Ambiental y II Congreso Nacional de Investigación en la Enseñanza de la Biología.

- Rodríguez, M. (2016). La huerta escolar: Un ambiente de Enseñanza para la comprensión del tópico generativo Red Trófica, dirigido a estudiantes de sexto grado. Maestría en Didácticas de las Ciencias, Universidad Autónoma de Colombia. Bogotá, Colombia.

- SIB (2016) Cifras de la biodiversidad. Recuperado de: htpp://sibcolombia.co

- Torres, K. (2014). La observación e ilustración de insectos como una estrategia para el reconocimiento y valoración de lo vivo. Departamento de Biología, Universidad Pedagógica Nacional, Bogotá, Colombia.

- Recomendadas para la Comprensión e Instrucción de la Conservación por el Comité de Educación de la Sociedad para la Biología de la Conservación 
Bio - grafía. Escritos sobre la Biología y su Enseñanza. ISSN 2027-1034

Edición Extraordinaria. p.p. 44 - 83

Memorias del IX Encuentro Nacional de Experiencias en Enseñanza de la Biología y la

Educación Ambiental. IV Congreso Nacional de Investigación en Enseñanza de la

Biología.

ANEXOS

Anexo 1. Cronograma base inicial.

\begin{tabular}{|c|c|c|c|c|}
\hline Sesión & $\begin{array}{c}\text { Hilo } \\
\text { conductor }\end{array}$ & Objetivo & Desempeño de comprensión & $\begin{array}{c}\text { Metas de } \\
\text { Comprensión }\end{array}$ \\
\hline 1 & $\begin{array}{l}\text { ¿Hay zonas } \\
\text { verdes en } \\
\text { mi colegio? } \\
\text { ¿Cuáles } \\
\text { son? }\end{array}$ & $\begin{array}{l}\text { Reconocer con } \\
\text { los estudiantes } \\
\text { del curso } 704 \\
\text { del CEDID } \\
\text { Ciudad Bolívar } \\
\text { las } \text { zonas } \\
\text { verdes de su } \\
\text { colegio. }\end{array}$ & $\begin{array}{l}\text { Realizar actividades de reconocimiento de } \\
\text { las zonas verdes en su colegio, con el fin de } \\
\text { tener una mirada más amplia sobre la } \\
\text { biodiversidad presente. Primer Taller } \\
\text { sensorial y de ilustración, tiene el fin de } \\
\text { sensibilizar y mostrar su personalidad a } \\
\text { partir de esa primera ilustración, que tomara } \\
\text { un papel importante para la siguiente } \\
\text { sesión. }\end{array}$ & $\begin{array}{l}\text { Los estudiantes } \\
\text { reconocerán las } \\
\text { zonas verdes de su } \\
\text { colegio como lugares } \\
\text { de interacción de } \\
\text { diferentes } \\
\text { organismos, entre } \\
\text { ellos los insectos. }\end{array}$ \\
\hline 2 & $\begin{array}{l}\text { ¿Qué es un } \\
\text { insecto? } \\
\text { ¿Cómo se } \\
\text { relaciona } \\
\text { con su } \\
\text { medio? } \\
\text { ¿Cómo la } \\
\text { ilustración } \\
\text { puede } \\
\text { aportar al } \\
\text { conocimient } \\
\text { o de los } \\
\text { insectos? }\end{array}$ & $\begin{array}{l}\text { Conocer la } \\
\text { biodiversidad } \\
\text { de insectos } \\
\text { asociada a las } \\
\text { zonas verdes } \\
\text { del Colegio } \\
\text { CEDID Ciudad } \\
\text { Bolívar a partir } \\
\text { de una } \\
\text { bitácora de } \\
\text { ilustraciones } \\
\text { que tenga en } \\
\text { cuenta la } \\
\text { identidad de } \\
\text { los } \\
\text { estudiantes. }\end{array}$ & $\begin{array}{l}\text { Base teórica sobre Biología y ecología de } \\
\text { insectos, también, sobre las diferentes } \\
\text { técnicas de ilustración a trabajar en la } \\
\text { bitácora, como son: puntillismo, tinta o } \\
\text { esfero, lápices colores, ecolín, crayón y } \\
\text { acuarelas. Por medio de acercamientos a } \\
\text { las zonas naturales, se observaran los } \\
\text { insectos presentes, si es necesario, se hará } \\
\text { el montaje de trampas para lograr una } \\
\text { captura viva y se tomaran las respectivas } \\
\text { fotografías para su próxima identificación. } \\
\text { Cada estudiante debe seleccionar un } \\
\text { insecto, que se identifique con él, tratando } \\
\text { en la medida de lo posible que sea diferente } \\
\text { al de los demás compañeros. Será } \\
\text { necesario utilizar la ilustración realizada en } \\
\text { el primer objetivo para realizar la portada de } \\
\text { la bitácora, ya que esta muestra la identidad } \\
\text { de cada estudiante. }\end{array}$ & \begin{tabular}{lr} 
Los estudiantes \\
relacionaran \\
biología del insecto \\
con el papel que \\
cumplen en el medio. \\
Los estudiantes \\
desarrollaran sus \\
habilidades \\
manuales y de \\
observación para \\
conocer los insectos \\
\multicolumn{2}{l}{ de su colegio. }
\end{tabular} \\
\hline 3 & $\begin{array}{l}\text { ¿Debo } \\
\text { cuidar los } \\
\text { insectos } \\
\text { que están } \\
\text { en las } \\
\text { zonas }\end{array}$ & $\begin{array}{l}\text { Entender la } \\
\text { importancia } \\
\text { ecológica de } \\
\text { los insectos en } \\
\text { las zonas } \\
\text { verdes del }\end{array}$ & $\begin{array}{l}\text { Se realizará un escrito con revisiones } \\
\text { documentales y buenos análisis que den } \\
\text { cuenta de la importancia de valorar y cuidar } \\
\text { los insectos y como aporta esto a la } \\
\text { biodiversidad de nuestro territorio. Mediante } \\
\text { las relaciones que se establezcan, fomentar }\end{array}$ & $\begin{array}{l}\text { Los estudiantes } \\
\text { desarrollaran } \\
\text { actitudes de } \\
\text { valoración y cuidado } \\
\text { de la biodiversidad }\end{array}$ \\
\hline
\end{tabular}


Bio - grafía. Escritos sobre la Biología y su Enseñanza. ISSN 2027-1034

Edición Extraordinaria. p.p. 44 - 83

Memorias del IX Encuentro Nacional de Experiencias en Enseñanza de la Biología y la

Educación Ambiental. IV Congreso Nacional de Investigación en Enseñanza de la Biología.

\begin{tabular}{|c|c|c|c|}
\hline $\begin{array}{l}\text { verdes de } \\
\text { mi colegio? } \\
\text { ¿Por qué? }\end{array}$ & $\begin{array}{l}\text { colegio para } \\
\text { brindar a los } \\
\text { estudiantes } \\
\text { elementos de } \\
\text { valoración }\end{array}$ & $\begin{array}{l}\text { diálogos para llegar a reflexiones tanto } \\
\text { grupales como individuales. }\end{array}$ & \\
\hline \multicolumn{4}{|c|}{$\begin{array}{l}\text { Anexo 2. Encuesta a estudiantes del curso } 804 \text { del Colegio CEDID Ciudad Bolívar.CEDID } \\
\text { CIUDAD BOLÍVAR } \\
\text { JORNADAMAÑ ANA } \\
\text { CURSO } 804\end{array}$} \\
\hline \multicolumn{4}{|c|}{$\begin{array}{l}\text { Edad: ___ Sexo: Hombre __ Mujer __ } \\
\text { Localidad: } \_ \text {Barrio: } \\
\text { 1. ¿Cuáles zonas verdes identifica usted en su escuela? }\end{array}$} \\
\hline \multicolumn{4}{|c|}{$\begin{array}{l}\text { 3. Si la respuesta es sí, ¿Qué clase de actividades ha realizado en estos espacios? ¿Han sido de } \\
\text { su agrado? }\end{array}$} \\
\hline \multicolumn{4}{|c|}{$\begin{array}{l}\text { 4. ¿Qué clase de actividades le gustaría realizar o seguir realizando en las zonas verdes } \\
\text { mencionadas? }\end{array}$} \\
\hline \multicolumn{4}{|c|}{$\begin{array}{l}\text { 5. ¿Practica o le llaman la atención alguna de las siguientes expresiones artísticas? (puede marcar } \\
\text { más de una) }\end{array}$} \\
\hline Grafiti & \multicolumn{3}{|c|}{ Dibujo } \\
\hline Música & \multicolumn{3}{|c|}{ Pintura } \\
\hline Literatura & \multicolumn{2}{|c|}{ Teatro } & \\
\hline \multicolumn{4}{|c|}{ Otra, ¿Cuál? } \\
\hline \multicolumn{4}{|c|}{$\begin{array}{l}\text { 6. Describa las que usted considere características propias de los } \\
\text { insectos. }\end{array}$} \\
\hline \multicolumn{4}{|c|}{$\begin{array}{l}\text { 7. ¿Qué insectos conoce? Y ¿En dónde los ha } \\
\text { visto? }\end{array}$} \\
\hline
\end{tabular}


Bio - grafía. Escritos sobre la Biología y su Enseñanza. ISSN 2027-1034

Edición Extraordinaria. p.p. 44 - 83

Memorias del IX Encuentro Nacional de Experiencias en Enseñanza de la Biología y la

Educación Ambiental. IV Congreso Nacional de Investigación en Enseñanza de la Biología.

8. Realice un dibujo de alguno de los insectos que conozca.

9. Para usted que es la biodiversidad

10. Considera que se debe cuidar y valorar la biodiversidad ¿Por qué?

Gracias por su colaboración 
Bio - grafía. Escritos sobre la Biología y su Enseñanza. ISSN 2027-1034

Edición Extraordinaria. p.p. 44 - 83

Memorias del IX Encuentro Nacional de Experiencias en Enseñanza de la Biología y la

Educación Ambiental. IV Congreso Nacional de Investigación en Enseñanza de la Biología.

Anexo 3. Rúbrica para el estudiante.

\section{Colegio CEDID Ciudad Bolívar}

\section{Curso 804 Jornada Mañana}

Rúbricas de Evaluación.

Material Elaborado por: Lorena Guerrero

\begin{tabular}{|c|c|c|c|c|c|}
\hline \multicolumn{6}{|c|}{ Primer Periodo } \\
\hline \multirow{2}{*}{$\begin{array}{c}\text { Dimensión } \\
\text { de } \\
\text { comprensió } \\
\mathbf{n}\end{array}$} & \multirow[t]{2}{*}{ Hilo conductor } & \multicolumn{4}{|c|}{ Descriptores } \\
\hline & & Nivel 1. Ingenuo & Nivel 2. Principiante & Nivel 3. Aprendiz & Nivel 4. Maestría \\
\hline & $\begin{array}{l}\text { ¿Cuáles son las } \\
\text { interacciones que se } \\
\text { presentan en las } \\
\text { zonas verdes de mi } \\
\text { colegio? }\end{array}$ & $\begin{array}{l}\text { Reconoce las zonas } \\
\text { verdes, sin embargo, } \\
\text { ignora los organismos } \\
\text { que se presentan y } \\
\text { por ende las } \\
\text { dinámicas } \\
\text { establecen. que }\end{array}$ & $\begin{array}{l}\text { Reconoce que en su } \\
\text { colegio hay zonas verdes, } \\
\text { aun cuando no las } \\
\text { identifica con claridad, } \\
\text { evidencia que hay } \\
\text { organismos allí presentes, } \\
\text { pero no establece } \\
\text { relaciones organismo- } \\
\text { medio. }\end{array}$ & $\begin{array}{l}\text { Reconoce la huerta como } \\
\text { una zona verde, pudiendo } \\
\text { describir algunas de las } \\
\text { relaciones de los } \\
\text { organismos que observa, } \\
\text { entendiendo este espacio } \\
\text { como sitio de interacciones } \\
\text { organismo-medio. }\end{array}$ & $\begin{array}{l}\text { Reconoce las zonas verdes } \\
\text { de su colegio como parte de } \\
\text { su territorio, donde se } \\
\text { presentan dinámicas entre el } \\
\text { ambiente y los organismos, } \\
\text { evidenciando interacciones } \\
\text { específicas, además se } \\
\text { reconoce a sí mismo como } \\
\text { un organismo que interactúa } \\
\text { con su medio. }\end{array}$ \\
\hline & $\begin{array}{c}\text { ¿Cuáles son las } \\
\text { características } \\
\text { propias de los } \\
\text { insectos? ¿Qué los } \\
\text { diferencia de otros }\end{array}$ & $\begin{array}{l}\text { No identifica las } \\
\text { características } \\
\text { propias de los } \\
\text { insectos, } \\
\text { evidenciando } \\
\text { dificultad al momento }\end{array}$ & $\begin{array}{l}\text { Crea relaciones de forma } \\
\text { y tamaño entre los } \\
\text { diferentes invertebrados } \\
\text { asumiéndolos como } \\
\text { insectos, por ello se le } \\
\text { dificulta } \\
\text { establecer }\end{array}$ & $\begin{array}{l}\text { Sabe que es un insecto, los } \\
\text { reconoce a simple vista, } \\
\text { sin embargo, suele integrar } \\
\text { otros invertebrados no } \\
\text { insectos en los ejemplos } \\
\text { que da, presentando }\end{array}$ & $\begin{array}{l}\text { ldentifica las características } \\
\text { propias de un insecto, } \\
\text { diferenciándolo de otros } \\
\text { invertebrados, } \\
\text { términos ananeja } \\
\text { incluso, observa los insectos }\end{array}$ \\
\hline
\end{tabular}


Bio - grafía. Escritos sobre la Biología y su Enseñanza. ISSN 2027-1034

Edición Extraordinaria. p.p. 44 - 83

Memorias del IX Encuentro Nacional de Experiencias en Enseñanza de la Biología y la

Educación Ambiental. IV Congreso Nacional de Investigación en Enseñanza de la Biología.

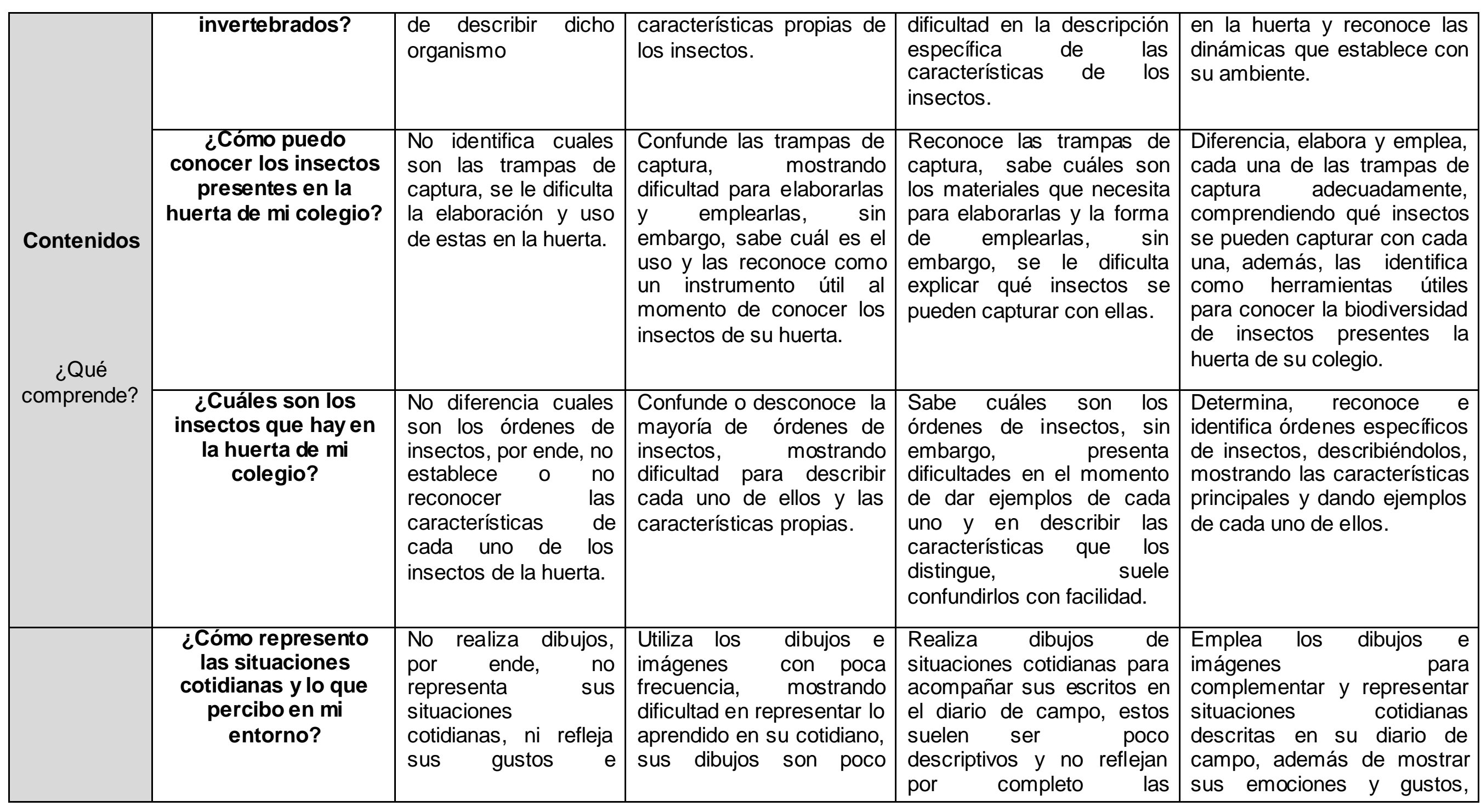


Bio - grafía. Escritos sobre la Biología y su Enseñanza. ISSN 2027-1034

Edición Extraordinaria. p.p. 44 - 83

Memorias del IX Encuentro Nacional de Experiencias en Enseñanza de la Biología y la

Educación Ambiental. IV Congreso Nacional de Investigación en Enseñanza de la Biología.

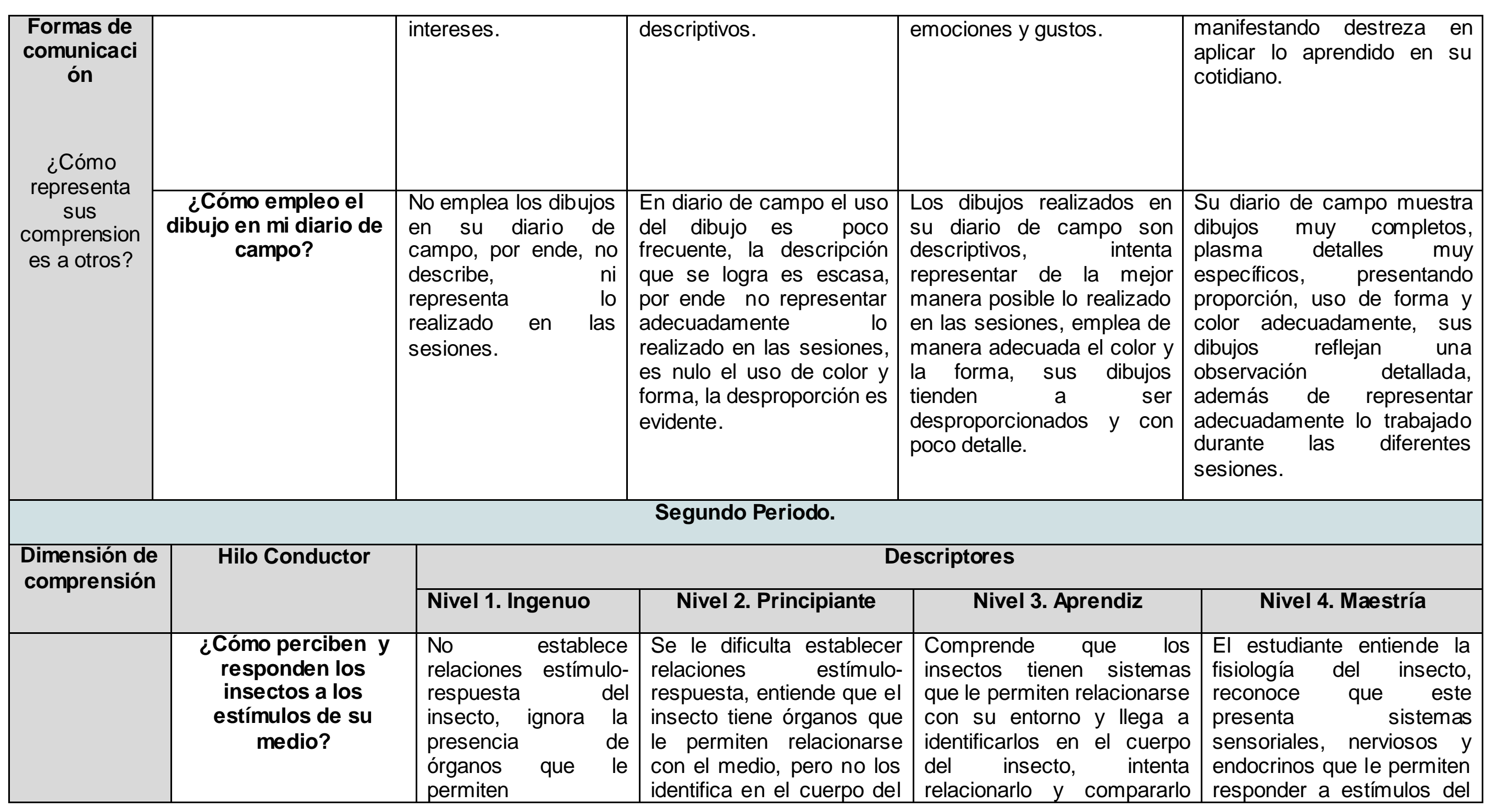


Bio - grafía. Escritos sobre la Biología y su Enseñanza. ISSN 2027-1034

Edición Extraordinaria. p.p. 44 - 83

Memorias del IX Encuentro Nacional de Experiencias en Enseñanza de la Biología y la

Educación Ambiental. IV Congreso Nacional de Investigación en Enseñanza de la Biología.

\begin{tabular}{|c|c|c|c|c|}
\hline & $\begin{array}{l}\text { relacionarse con su } \\
\text { medio. }\end{array}$ & $\begin{array}{l}\text { mismo, no extrapola sus } \\
\text { conocimientos con otros } \\
\text { organismos. }\end{array}$ & $\begin{array}{l}\text { con otros organismos, sin } \\
\text { embargo, ignora las } \\
\text { similitudes que puede tener } \\
\text { con sigo mismo. }\end{array}$ & $\begin{array}{l}\text { ambiente e interactuar con } \\
\text { este, tiene la capacidad de } \\
\text { generar relaciones entre } \\
\text { estímulo- respuesta y } \\
\text { extrapolar } \\
\text { conocimientos a otros } \\
\text { organismos, llegando a } \\
\text { ejemplificar y establecer } \\
\text { comparativos incluso con sí } \\
\text { mismo. }\end{array}$ \\
\hline $\begin{array}{c}\text { ¿Qué importancia } \\
\text { tienen los insectos en } \\
\text { la huerta y en el } \\
\text { mundo? }\end{array}$ & $\begin{array}{lr}\text { No } & \text { establece } \\
\text { relaciones } & \text { del } \\
\text { insecto con su } & \text { su } \\
\text { medio, por ello no } \\
\text { comprende cómo } \\
\text { estos pueden o no } \\
\text { ser significativos } \\
\text { incluso para su } \\
\text { existencia misma. }\end{array}$ & $\begin{array}{l}\text { Establece relaciones } \\
\text { simples entre los insectos } \\
\text { y su medio, por ello, no } \\
\text { dimensiona la importancia } \\
\text { de estos en el mundo, y } \\
\text { no le da relevancia a las } \\
\text { implicaciones que tendría } \\
\text { el humano y de los demás } \\
\text { organismos si los insectos } \\
\text { llegaran a desaparecer. }\end{array}$ & $\begin{array}{l}\text { Establece relaciones } \\
\text { insecto- medio, entiende la } \\
\text { importancia del insecto en } \\
\text { el mundo y cómo se vería } \\
\text { afectado el ambiente si } \\
\text { estos llegaran a } \\
\text { desaparecer, sin embargo, } \\
\text { se le dificulta extrapolar } \\
\text { estos conocimientos a su } \\
\text { realidad inmediata. }\end{array}$ & $\begin{array}{l}\text { Establece las relaciones } \\
\text { intraespecíficas } \\
\text { interespecíficas entre los } \\
\text { diferentes insectos y su } \\
\text { medio, comprendiendo de } \\
\text { esta manera, el papel } \\
\text { ecológico que cumplen y la } \\
\text { importancia que tienen en } \\
\text { las dinámicas del planeta, y } \\
\text { que la supervivencia del } \\
\text { humano depende en gran } \\
\text { medida de la presencia de } \\
\text { insectos en el mundo. }\end{array}$ \\
\hline $\begin{array}{c}\text { ¿Cómo y por qué se } \\
\text { deben valorar y } \\
\text { cuidar los insectos } \\
\text { presentes en la } \\
\text { huerta del colegio? }\end{array}$ & $\begin{array}{l}\text { Asume cada } \\
\text { organismo como un } \\
\text { individuo que no se } \\
\text { relaciona, por ello, no } \\
\text { ve implicación entre } \\
\text { la existencia o no de } \\
\text { las especies, no se } \\
\text { interesa por la }\end{array}$ & $\begin{array}{l}\text { No encuentra diferencia } \\
\text { entre la presencia o no de } \\
\text { insectos, por ello no } \\
\text { reconoce las implicaciones } \\
\text { ecológicas que habrían } \\
\text { con su desaparición, por } \\
\text { ende no plantea } \\
\text { estrategias de valoración y }\end{array}$ & $\begin{array}{l}\text { Entiende la importancia de } \\
\text { los insectos en la huerta y } \\
\text { en el planeta y el daño } \\
\text { ecológico que habría si } \\
\text { llegaran a desaparecer, por } \\
\text { las relaciones tan estrechas } \\
\text { que presentan con su } \\
\text { entorno, por ello intenta }\end{array}$ & $\begin{array}{l}\text { Reconoce con claridad } \\
\text { cuáles insectos hay en su } \\
\text { huerta, como estos aportan } \\
\text { a la dinámica ecosistémica } \\
\text { y si son benéficos o no } \\
\text { para las plantas o demás } \\
\text { organismos que allí se } \\
\text { encuentran, entendiendo }\end{array}$ \\
\hline
\end{tabular}


Bio - grafía. Escritos sobre la Biología y su Enseñanza. ISSN 2027-1034

Edición Extraordinaria. p.p. 44 - 83

Memorias del IX Encuentro Nacional de Experiencias en Enseñanza de la Biología y la

Educación Ambiental. IV Congreso Nacional de Investigación en Enseñanza de la Biología.

\begin{tabular}{|c|c|c|c|c|c|}
\hline $\begin{array}{c}\text { Contenidos } \\
\text { ¿Qué } \\
\text { comprende? }\end{array}$ & & $\begin{array}{l}\text { valoración y cuidado } \\
\text { de los insectos y } \\
\text { demás organismos. }\end{array}$ & $\begin{array}{l}\text { cuidado hacia estos } \\
\text { organismos. }\end{array}$ & $\begin{array}{l}\text { plantear estrategias para la } \\
\text { conservación de los } \\
\text { insectos. }\end{array}$ & $\begin{array}{l}\text { que son necesarios para } \\
\text { las dinámicas del mundo, } \\
\text { plantea estrategias viables } \\
\text { para la conservación de los } \\
\text { insectos, propiciando } \\
\text { valoración y cuidado no } \\
\text { solo hacia los insectos, } \\
\text { sino también hacia toda la } \\
\text { biodiversidad. }\end{array}$ \\
\hline & $\begin{array}{c}\text { ¿Cuál es la diferencia } \\
\text { entre un dibujo y una } \\
\text { ilustración? y } \\
\text { ¿Cuáles son las } \\
\text { técnicas de } \\
\text { ilustración y cómo } \\
\text { puedo emplearlas? }\end{array}$ & $\begin{array}{l}\text { No reconoce } \\
\text { diferencia alguna } \\
\text { entre dibujo e } \\
\text { ilustración, por ello, } \\
\text { no reconoce las } \\
\text { técnicas de manera } \\
\text { precisa. }\end{array}$ & $\begin{array}{lr}\text { Su discurso y } & \text { sus } \\
\text { prácticas demuestran que } \\
\text { emplea la palabra } \\
\text { ilustración y } \\
\text { indistintamente, } & \text { dibujo } \\
\text { embargo, logra diferenciar } \\
\text { las técnicas empleadas en } \\
\text { la ilustración. }\end{array}$ & $\begin{array}{l}\text { Reconoce la ilustración } \\
\text { como una expresión de arte } \\
\text { empleada para } \\
\text { representaciones } \\
\text { específicas de organismos, } \\
\text { sin embargo, al momento } \\
\text { de la práctica denota } \\
\text { confusión para diferenciar } \\
\text { un dibujo y una ilustración. } \\
\text { Reconoce las técnicas de } \\
\text { ilustración e intenta } \\
\text { emplearlas de la manera } \\
\text { posible. }\end{array}$ & $\begin{array}{l}\text { Reconoce el dibujo como } \\
\text { una representación artística } \\
\text { que muestra sus } \\
\text { emociones, gustos e } \\
\text { intereses y la ilustración } \\
\text { como una expresión del } \\
\text { arte que le permite } \\
\text { representar un organismo } \\
\text { destacando características } \\
\text { específicas, para su } \\
\text { posterior clasificación, sin } \\
\text { dejar de lado, su expresión } \\
\text { y autenticidad. Diferencia } \\
\text { las técnicas propias de la } \\
\text { ilustración, sabe cómo y } \\
\text { porque emplearlas de } \\
\text { manera adecuada y cuáles } \\
\text { son los materiales para } \\
\text { realizar cada una de estas } \\
\text { técnicas. }\end{array}$ \\
\hline
\end{tabular}


Edición Extraordinaria. p.p. 44 - 83

Memorias del IX Encuentro Nacional de Experiencias en Enseñanza de la Biología y la

Educación Ambiental. IV Congreso Nacional de Investigación en Enseñanza de la Biología.

\begin{tabular}{|c|c|c|c|c|c|}
\hline \multirow[t]{3}{*}{$\begin{array}{l}\text { Formas de } \\
\text { comunicació } \\
\text { n } \\
\\
\text { ¿Cómo } \\
\text { representa sus } \\
\text { comprensione } \\
\text { s a otros? }\end{array}$} & $\begin{array}{l}\text { ¿Cómo empleó las } \\
\text { técnicas de } \\
\text { ilustración para } \\
\text { representar las } \\
\text { características } \\
\text { propias de mi } \\
\text { insecto? }\end{array}$ & $\begin{array}{l}\text { No emplea ni } \\
\text { distingue cada una } \\
\text { de las técnicas de } \\
\text { ilustración, por ello } \\
\text { sus representaciones } \\
\text { no logran mostrar las } \\
\text { características de su } \\
\text { insecto. }\end{array}$ & $\begin{array}{l}\text { Sabe cuáles son las } \\
\text { técnicas de ilustración, } \\
\text { pero se le dificulta } \\
\text { emplearlas de manera } \\
\text { adecuada, por ello sus } \\
\text { ilustraciones carecen de } \\
\text { rigor y no representan las } \\
\text { características propias de } \\
\text { su insecto. }\end{array}$ & $\begin{array}{l}\text { Maneja las técnicas de } \\
\text { ilustración de manera } \\
\text { adecuada, sin embargo, } \\
\text { aún se le dificulta reconocer } \\
\text { en qué momento debe } \\
\text { aplicar cada una, sus } \\
\text { representaciones son claras } \\
\text { y permiten observar } \\
\text { características propias de } \\
\text { su insecto. }\end{array}$ & $\begin{array}{l}\text { Hace uso de las técnicas } \\
\text { de ilustración } \\
\text { correctamente y sabe } \\
\text { cómo, por qué y cuándo } \\
\text { emplearlas, logrando de } \\
\text { esta manera representar su } \\
\text { insecto muy claramente, } \\
\text { permitiéndole mostrar las } \\
\text { características específicas, } \\
\text { la fisiología y partes } \\
\text { sensoriales importantes de } \\
\text { forma clara. }\end{array}$ \\
\hline & $\begin{array}{l}\text { ¿Cómo demuestro mi } \\
\text { personalidad, gustos } \\
\text { e intereses en la } \\
\text { portada de mi } \\
\text { bitácora de } \\
\text { ilustraciones? }\end{array}$ & $\begin{array}{l}\text { La bitácora no } \\
\text { cumple con las } \\
\text { indicaciones ya que } \\
\text { no refleja los gustos, } \\
\text { interés y } \\
\text { personalidad, } \\
\text { además no emplea el } \\
\text { color, forma y } \\
\text { proporción de } \\
\text { manera adecuada. }\end{array}$ & $\begin{array}{l}\text { Su bitácora está bien } \\
\text { estructurada en cuanto } \\
\text { forma, pero no refleja los } \\
\text { gustos e intereses de } \\
\text { quien la elabora, } \\
\text { enfocándose solo en el } \\
\text { insecto elegido. }\end{array}$ & $\begin{array}{l}\text { Su portada refleja y expresa } \\
\text { su personalidad, gustos e } \\
\text { intereses, se evidencia el } \\
\text { esfuerzo por cautivar, deja } \\
\text { en un segundo plano el } \\
\text { organismo que está } \\
\text { representando, } \\
\text { embargo, tiene un uso } \\
\text { adecuado del espacio y de } \\
\text { forma. }\end{array}$ & $\begin{array}{l}\text { Impacta en la portada de } \\
\text { su bitácora de } \\
\text { ilustraciones, ya que } \\
\text { muestra de manera } \\
\text { creativa su personalidad, } \\
\text { sus gustos e intereses, sin } \\
\text { dejar de lado el organismo } \\
\text { que está representando, el } \\
\text { uso adecuado del color, la } \\
\text { forma y las proporciones, } \\
\text { llegando a cautivar al } \\
\text { espectador. }\end{array}$ \\
\hline & $\begin{array}{l}\text { ¿Evidencio } \\
\text { apropiación de las } \\
\text { técnicas de } \\
\text { ilustración, } \\
\text { aplicándolas en mi } \\
\text { diario de campo? }\end{array}$ & $\begin{array}{l}\text { No } \\
\text { ilustraciones en su } \\
\text { diario de campo, } \\
\text { reflejando el poco } \\
\text { dominio adquirido de } \\
\text { las técnicas. }\end{array}$ & $\begin{array}{l}\text { Usa las ilustraciones } \\
\text { indistintamente con los } \\
\text { dibujos, no emplea de } \\
\text { manera adecuada las } \\
\text { técnicas desarrolladas. }\end{array}$ & $\begin{array}{l}\text { Emplea con frecuencia } \\
\text { ilustraciones en su diario de } \\
\text { campo, intentando } \\
\text { desarrollar las técnicas ya } \\
\text { trabajadas de la mejor } \\
\text { manera posible. }\end{array}$ & $\begin{array}{l}\text { Emplea distintivamente los } \\
\text { dibujos de las ilustraciones } \\
\text { en su cuaderno de campo, } \\
\text { cuando realiza ilustraciones } \\
\text { lo hace con el rigor y con } \\
\text { las técnicas ya } \\
\text { desarrolladas en las }\end{array}$ \\
\hline
\end{tabular}


Edición Extraordinaria. p.p. 44 - 83

Memorias del IX Encuentro Nacional de Experiencias en Enseñanza de la Biología y la Educación Ambiental. IV Congreso Nacional de Investigación en Enseñanza de la Biología.

\begin{tabular}{|l|l|l|l|l|l|}
\hline & & & & & diferentes sesiones. \\
\hline
\end{tabular}

Anexo 4. Cronograma final, reestructurado a partir de las necesidades del contexto.

\begin{tabular}{|c|c|c|c|c|c|}
\hline Sesión & $\begin{array}{l}\text { Hilo } \\
\text { conductor }\end{array}$ & Tópico Generativo & $\begin{array}{l}\text { Desempeño } \\
\text { comprensión }\end{array}$ & Metas de Comprensión & Aporte al Proyecto Síntesis \\
\hline 1 & $\begin{array}{l}\text { ¿Cuáles son } \\
\text { las } \\
\text { interacciones } \\
\text { que se } \\
\text { presentan en } \\
\text { las zonas } \\
\text { verdes de mi } \\
\text { colegio? } \\
\text { ¿Qué } \\
\text { insectos hay } \\
\text { en las zonas } \\
\text { verdes de mi } \\
\text { colegio? }\end{array}$ & $\begin{array}{l}\text { Reconocer con los } \\
\text { estudiantes las zonas } \\
\text { verdes de su colegio, } \\
\text { como parte de su } \\
\text { territorio. } \\
\text { Comprender que los } \\
\text { insectos son } \\
\text { organismos vivos, } \\
\text { que interactúan y } \\
\text { hacen parte de la } \\
\text { huerta. } \\
\text { Bibliografía } \\
\text { recomendada: } \\
\text {-Ramírez, J. La }\end{array}$ & $\begin{array}{l}\text { Realizar una actividad corta } \\
\text { de sensibilización, donde los } \\
\text { estudiantes cierren sus ojos } \\
\text { e intenten conectarse con el } \\
\text { medio, mientras el profesor } \\
\text { explica la importancia de } \\
\text { este espacio para ellos y } \\
\text { para los demás organismos } \\
\text { que interactúan en él. } \\
\text { También tiene como } \\
\text { finalidad, entender las zonas } \\
\text { verdes del colegio como } \\
\text { parte del territorio, además } \\
\text { de conectarse con los } \\
\text { organismos allípresentes. }\end{array}$ & $\begin{array}{l}\text { Los estudiantes reconocerán } \\
\text { las zonas verdes de su colegio } \\
\text { como parte de su territorio y } \\
\text { como lugares de interacción } \\
\text { de diferentes organismos, en } \\
\text { especial de los insectos, } \\
\text { reconociéndolos como la } \\
\text { otredad, es decir como } \\
\text { organismos vivos, que } \\
\text { interactúan y necesitan de un } \\
\text { espacio para vivir. } \\
\text { También, los estudiantes } \\
\text { expresaran sus ideas previas } \\
\text { sobre lo que ellos consideran }\end{array}$ & $\begin{array}{l}\text { Con el desarrollo del taller } \\
\text { sensibilización se busca forjar en } \\
\text { el estudiante sentido de } \\
\text { pertenecía con su territorio, lo } \\
\text { cual facilitará las actividades a } \\
\text { desarrollar durante las diferentes } \\
\text { sesiones. } \\
\text { El resultado de la primera } \\
\text { ilustración permitirá un ejercicio } \\
\text { de Autoevaluación, donde el } \\
\text { estudiante podrá evidenciar el } \\
\text { progreso que tuvo durante las } \\
\text { diferentes sesiones. }\end{array}$ \\
\hline
\end{tabular}




\section{Bio - grafía. Escritos sobre la Biología y su Enseñanza. ISSN 2027-1034}

Edición Extraordinaria. p.p. 44 - 83

Memorias del IX Encuentro Nacional de Experiencias en Enseñanza de la Biología y la

Educación Ambiental. IV Congreso Nacional de Investigación en Enseñanza de la Biología.

\begin{tabular}{|c|c|c|c|c|c|}
\hline & & 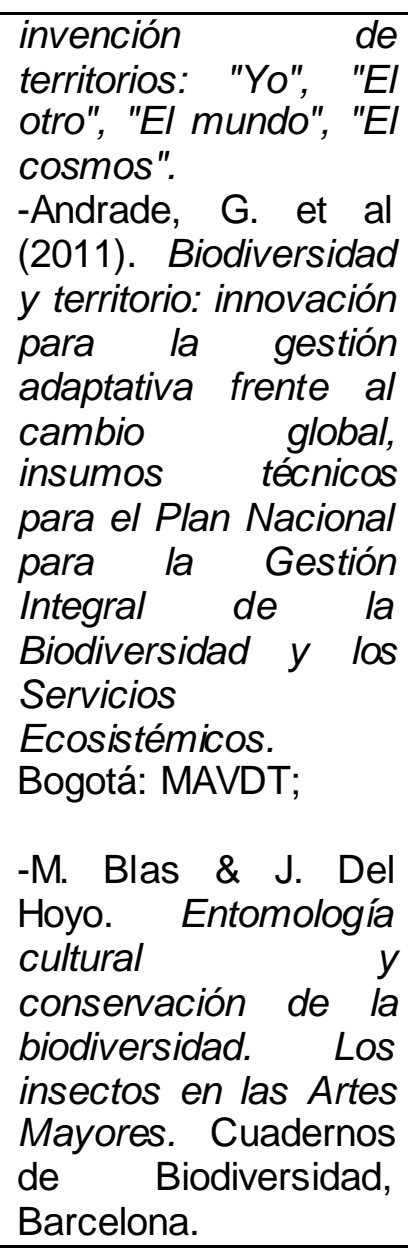 & $\begin{array}{l}\text { Los estudiantes realizarán } \\
\text { una primera ilustración del } \\
\text { insecto que más llame su } \\
\text { atención, de esta manera se } \\
\text { busca que los estudiantes } \\
\text { muestren su personalidad e } \\
\text { interactúen con la huerta, } \\
\text { también, tienen la intención } \\
\text { de conocer las ideas previas } \\
\text { de los estudiantes sobre qué } \\
\text { es un insecto. }\end{array}$ & $\begin{array}{l}\text { es un insecto y sus nociones } \\
\text { básicas de ilustración. }\end{array}$ & $\begin{array}{l}\text { Trabajo en casa: Consultar la } \\
\text { taxonomía y características } \\
\text { principales del insecto ilustrado. }\end{array}$ \\
\hline 2 & $\begin{array}{l}\text { ¿Cuáles son } \\
\text { las } \\
\text { característica } \\
\text { s propias de }\end{array}$ & $\begin{array}{lr}\text { Conocer } & \text { la } \\
\text { clasificación de los } \\
\text { invertebrados, y de } \\
\text { los Phylum } & \text { que } \\
\text { conforman } & \text { este } \\
\end{array}$ & \begin{tabular}{lrrr} 
Con ayuda de & un mapa \\
conceptual (Ver Anexo & $1)$ \\
será & \multicolumn{2}{c}{ explicada } & la \\
clasificación & de & los \\
invertebrados, & de & esta \\
\end{tabular} & $\begin{array}{l}\text { Los estudiantes establecerán } \\
\text { diferencias entre los Phylum } \\
\text { pertenecientes a a los } \\
\text { invertebrados, pudiendo de } \\
\text { esta manera reconocer los }\end{array}$ & $\begin{array}{l}\text { Con esta Clase teórica se dejará } \\
\text { como insumo un mapa } \\
\text { conceptual o guía básica de los } \\
\text { diferentes Phylum que conforman } \\
\text { a los invertebrados, y las }\end{array}$ \\
\hline
\end{tabular}




\section{Bio - grafía. Escritos sobre la Biología y su Enseñanza. ISSN 2027-1034}

Edición Extraordinaria. p.p. 44 - 83

Memorias del IX Encuentro Nacional de Experiencias en Enseñanza de la Biología y la

Educación Ambiental. IV Congreso Nacional de Investigación en Enseñanza de la Biología.

\begin{tabular}{|c|c|c|c|c|c|}
\hline & $\begin{array}{l}\text { los insectos? } \\
\text { ¿Qué los } \\
\text { diferencia de } \\
\text { otros } \\
\text { invertebrado } \\
\text { s? }\end{array}$ & $\begin{array}{l}\text { grupo, haciendo } \\
\text { énfasis en las clases } \\
\text { de artrópoda, para } \\
\text { determinar las } \\
\text { características } \\
\text { específicas de un } \\
\text { insecto. } \\
\text { Bibliografía } \\
\text { recomendada: } \\
\text {-Brusca, R \& Brusca, } \\
\text { G. } \\
\text { Invertebrados. 2005. } \\
\text { Edición. Ed. McGraw- } \\
\text { Hill. España. } \\
\text {-Willmer, P. } 1990 . \\
\text { Invertebrate } \\
\text { Relationships. } \\
\text { Patterns in animal } \\
\text { evolution. Cambridge } \\
\text { University. }\end{array}$ & $\begin{array}{l}\text { manera se confrontaran las } \\
\text { ideas previas de los } \\
\text { estudiantes sobre los } \\
\text { insectos, comprendiendo } \\
\text { qué es un artrópodo, qué lo } \\
\text { caracteriza y cómo poder } \\
\text { diferenciarlo. } \\
\text { Luego de explicar el mapa } \\
\text { conceptual se hará un juego } \\
\text { donde los estudiantes } \\
\text { realizarán grupos, y a cada } \\
\text { grupo se le entregarán } 3 \\
\text { imágenes de diferentes } \\
\text { invertebrados y ellos tendrán } \\
\text { que ubicarlos en el Phylum o } \\
\text { Clase correspondiente, de } \\
\text { esta manera se evidenciará } \\
\text { la comprensión teórica. }\end{array}$ & $\begin{array}{l}\text { organismos escogidos en la } \\
\text { huerta y determinar si } \\
\text { pertenecen a la clase insecta } \\
\text { o no. }\end{array}$ & $\begin{array}{l}\text { características propias de cada } \\
\text { uno, el cual será de gran ayuda } \\
\text { para las diferentes sesiones. } \\
\text { Trabajo en casa: } \\
\text { Consultar que es la Van } \\
\text { Someren- Rydon, las trampas de } \\
\text { caída, la jama y trampas activas. }\end{array}$ \\
\hline 3 & $\begin{array}{l}\text { ¿Cómo } \\
\text { puedo } \\
\text { conocer la } \\
\text { biodiversidad } \\
\text { de insectos } \\
\text { presentes en } \\
\text { la huerta de } \\
\text { mi colegio? }\end{array}$ & $\begin{array}{l}\text { Aprender sobre las } \\
\text { trampas de captura } \\
\text { de insectos y cómo } \\
\text { con ellas se puede } \\
\text { aportar al } \\
\text { conocimiento de las } \\
\text { especies de insectos } \\
\text { presentes en la } \\
\text { huerta. } \\
\text { Bibliografía } \\
\text { recomendada: } \\
\text {-Gibb, T. \& Oseto, C. } \\
\text { 2006. Arthropod }\end{array}$ & $\begin{array}{l}\text { Para retomar el trabajo en } \\
\text { casa propuesto en la sesión } \\
\text { anterior se realiza una } \\
\text { explicación general de las } \\
\text { trampas de captura, donde } \\
\text { los estudiantes harán una } \\
\text { lluvia de ideas sobre las } \\
\text { funciones y los insectos que } \\
\text { se pueden colectar con cada } \\
\text { trampa. } \\
\text { Luego de la explicación, los } \\
\text { estudiantes se dividirán en } \\
\text { dos grandes grupos, según }\end{array}$ & $\begin{array}{l}\text { Los estudiantes conocerán las } \\
\text { diferentes trampas de captura } \\
\text { de insectos reconociendo } \\
\text { estas como un instrumento } \\
\text { viable para el conocimiento de } \\
\text { la biodiversidad de su huerta. }\end{array}$ & $\begin{array}{l}\text { Con esta actividad se busca que } \\
\text { los estudiantes comprendan que } \\
\text { se puede conocer la } \\
\text { biodiversidad de su colegio sin } \\
\text { recurrir al sacrificio de } \\
\text { especímenes. } \\
\text { Trabajo en casa: Traer los } \\
\text { materiales para realizar las } \\
\text { trampas para capturar insectos. }\end{array}$ \\
\hline
\end{tabular}




\section{Bio - grafía. Escritos sobre la Biología y su Enseñanza. ISSN 2027-1034}

Edición Extraordinaria. p.p. 44 - 83

Memorias del IX Encuentro Nacional de Experiencias en Enseñanza de la Biología y la

Educación Ambiental. IV Congreso Nacional de Investigación en Enseñanza de la Biología.

\begin{tabular}{|c|c|c|c|c|c|}
\hline & & 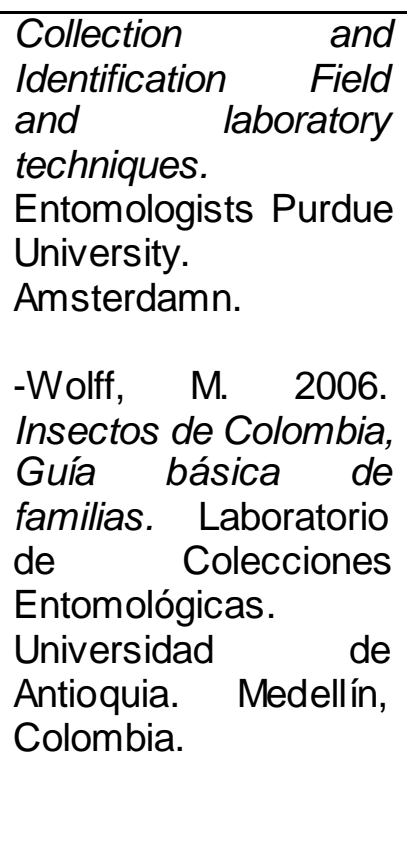 & $\begin{array}{l}\text { el tipo de hábito (Terrestre o } \\
\text { Volador) del insecto escogido } \\
\text { e ilustrado en la huerta la } \\
\text { primera sesión, estos grupos } \\
\text { se subdividirán formando así } \\
4 \text { o } 5 \text { grupos según el interés } \\
\text { particular. } \\
\text { A cada grupo se le asignará } \\
\text { una trampa de captura y se } \\
\text { le entregará una copia (Ver } \\
\text { anexo 1) donde se explica el } \\
\text { tipo de trampa, cómo hacerla } \\
\text { y cómo montarla, con esto, } \\
\text { los estudiantes deberán } \\
\text { escribir en su cuaderno los } \\
\text { materiales necesarios para } \\
\text { construirla y hacer el dibujo, } \\
\text { para su posterior } \\
\text { elaboración. }\end{array}$ & & \\
\hline 4 & $\begin{array}{l}\text { ¿Cómo } \\
\text { puedo } \\
\text { elaborar las } \\
\text { trampas de } \\
\text { captura? }\end{array}$ & $\begin{array}{l}\text { Interactuar con los } \\
\text { compañeros y } \\
\text { construir las trampas } \\
\text { para captura de } \\
\text { insectos dependiendo } \\
\text { del tipo de hábito del } \\
\text { insecto que se ilustró } \\
\text { (Volador o terrestre). }\end{array}$ & $\begin{array}{l}\text { Con los materiales } \\
\text { propuestos la clase pasada, } \\
\text { y con ayuda de los } \\
\text { compañeros se elaboran las } \\
\text { tramas para captura de } \\
\text { insectos, teniendo como guía } \\
\text { las copias suministradas la } \\
\text { clase anterior. } \\
\text { La idea es trabajar en un } \\
\text { espacio abierto, por ello, } \\
\text { luego de revisar que los } \\
\text { estudiantes tengan tanto los } \\
\text { materiales como la guía, } \\
\text { serán llevados a la cancha }\end{array}$ & $\begin{array}{l}\text { Los estudiantes forjarán lazos } \\
\text { de confianza con sus } \\
\text { compañeros por medio del } \\
\text { trabajo en grupo. } \\
\text { También podrán en práctica } \\
\text { su trabajo manual, dando } \\
\text { como resultado una trampa de } \\
\text { captura, que permitirá el } \\
\text { conocimiento de la } \\
\text { biodiversidad de insectos de } \\
\text { su colegio. }\end{array}$ & $\begin{array}{l}\text { Esta sesión busca enriquecer la } \\
\text { relación de los estudiantes, } \\
\text { permitiéndoles fortalecer sus } \\
\text { lazos, lo cual será muy } \\
\text { importante para el desarrollo de } \\
\text { las diferentes sesiones. } \\
\text { Proporcionará, también, una } \\
\text { trampa de captura que nos } \\
\text { permita conocer la biodiversidad } \\
\text { de insectos presentes en la } \\
\text { huerta. } \\
\text { Trabajo en casa: }\end{array}$ \\
\hline
\end{tabular}


Bio - grafía. Escritos sobre la Biología y su Enseñanza. ISSN 2027-1034

Edición Extraordinaria. p.p. 44 - 83

Memorias del IX Encuentro Nacional de Experiencias en Enseñanza de la Biología y la

Educación Ambiental. IV Congreso Nacional de Investigación en Enseñanza de la Biología.

\begin{tabular}{|c|c|c|c|c|c|}
\hline & & & $\begin{array}{l}\text { de futbol, donde se } \\
\text { distribuirán por grupos en el } \\
\text { espacio y se procederá a la } \\
\text { elaboración de las trampas } \\
\text { asignadas a cada grupo la } \\
\text { clase anterior, se debe tener } \\
\text { en cuenta que los } \\
\text { estudiantes que se les } \\
\text { asignó la trampa de caída y } \\
\text { la captura manual, no deben } \\
\text { elaborar como tal una } \\
\text { trampa, estos grupos } \\
\text { ayudarán a sus compañeros. }\end{array}$ & & $\begin{array}{l}\text { En caso de no haber terminado } \\
\text { las trampas, deben traerlas } \\
\text { elaboradas en su totalidad la } \\
\text { siguiente sesión, los estudiantes } \\
\text { que tengan trampas pasivas (Van } \\
\text { Someren Rydon y Trampas de } \\
\text { caída) deben traer el cebo } \\
\text { debidamente fermentado, puede } \\
\text { ser pescado y carne sellados } \\
\text { herméticamente mínimo por } 72 \\
\text { horas }\end{array}$ \\
\hline 5 & $\begin{array}{l}\text { ¿Cuál es la } \\
\text { manera } \\
\text { adecuada de } \\
\text { emplear las } \\
\text { trampas para } \\
\text { lograr una } \\
\text { buena } \\
\text { captura de } \\
\text { los } \\
\text { organismos } \\
\text { presentes en } \\
\text { la huerta? }\end{array}$ & $\begin{array}{l}\text { Emplear de manera } \\
\text { adecuada las trampas } \\
\text { de captura, } \\
\text { entendiendo el } \\
\text { porqué del tiempo de } \\
\text { espera, para que el } \\
\text { uso del cebo y cómo } \\
\text { funciona la trampa en } \\
\text { general. }\end{array}$ & $\begin{array}{l}\text { Al tener las trampas } \\
\text { totalmente terminadas, los } \\
\text { estudiantes se dirigirán a la } \\
\text { huerta, allí serán montadas } \\
\text { las trampas pasivas, es } \\
\text { decir, las } 2 \text { Van Someren- } \\
\text { Rydon será puestas en los } \\
\text { árboles, las trampas de caída } \\
\text { serán puestas en lugares } \\
\text { estratégicos como son el } \\
\text { invernadero, entre otros, las } \\
\text { trampas activas como la } \\
\text { jama, el aspirador y las } \\
\text { pinzas serán usadas cuando } \\
\text { se recojan las trampas, por } \\
\text { ahora los estudiantes que } \\
\text { pertenezcan a esos grupos } \\
\text { deberán colaborar a sus } \\
\text { compañeros a montar las }\end{array}$ & $\begin{array}{l}\text { Se entenderá como es el uso } \\
\text { adecuado de las trampas de } \\
\text { captura, la función del cebo y } \\
\text { los tiempos de espera para } \\
\text { lograr una buena captura que } \\
\text { permita conocer los insectos } \\
\text { que se encuentran en la } \\
\text { huerta. }\end{array}$ & $\begin{array}{l}\text { Trabajo en casa: } \\
\text { Traer frascos para muestras de } \\
\text { orina, o frascos de compota } \\
\text { limpios, para recoger las } \\
\text { muestras que hayan caído en las } \\
\text { trampas de captura. }\end{array}$ \\
\hline
\end{tabular}


Bio - grafía. Escritos sobre la Biología y su Enseñanza. ISSN 2027-1034

Edición Extraordinaria. p.p. 44 - 83

Memorias del IX Encuentro Nacional de Experiencias en Enseñanza de la Biología y la

Educación Ambiental. IV Congreso Nacional de Investigación en Enseñanza de la Biología.

\begin{tabular}{|c|c|c|c|c|c|}
\hline & & & $\begin{array}{l}\text { trampas. } \\
\text { Es importante colocar los } \\
\text { cebos debidamente } \\
\text { fermentados, las trampas } \\
\text { deberán dejarse de } 24 \text { a } 32 \\
\text { horas, de esta manera se } \\
\text { dará un tiempo de espera } \\
\text { óptimo para que los } \\
\text { organismos caigan en las } \\
\text { trampas. }\end{array}$ & & \\
\hline 6 & $\begin{array}{l}\text { ¿Son las } \\
\text { trampas la } \\
\text { mejor opción } \\
\text { para conocer } \\
\text { los insectos } \\
\text { de la huerta? }\end{array}$ & 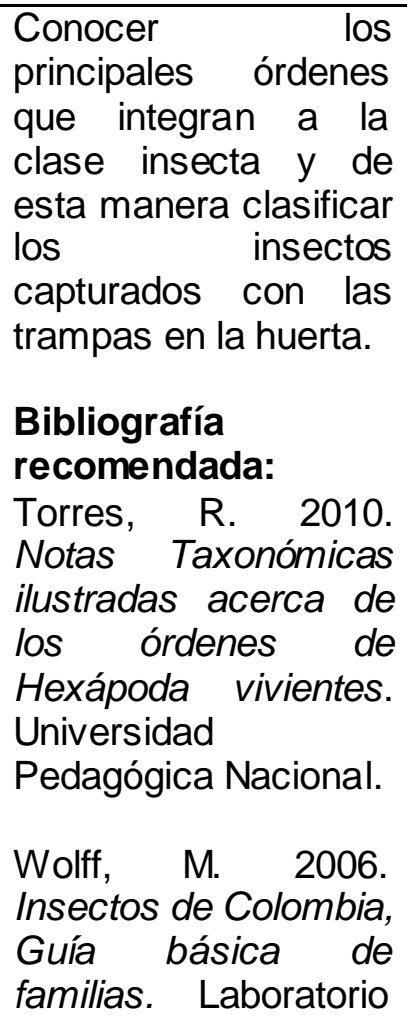 & $\begin{array}{l}\text { Pasadas las } 24 \text { o } 32 \text { horas, } \\
\text { se procederá a recolectar las } \\
\text { muestras obtenidas en las } \\
\text { trampas, para ello iremos a } \\
\text { la huerta, en los frascos de } \\
\text { orina o de compota limpios } \\
\text { se guardaran los } \\
\text { especímenes que hayan } \\
\text { escogido los estudiantes, } \\
\text { cada uno debe escoger un } \\
\text { insecto diferente, debe } \\
\text { marcar el frasco son su } \\
\text { nombre. } \\
\text { Los estudiantes que tienen } \\
\text { las trampas activas (pinzas, } \\
\text { aspirador y jama) deberán } \\
\text { realizar su muestreo } \\
\text { mientras los otros grupos } \\
\text { recogen lo que callo en sus } \\
\text { trampas pasivas. } \\
\text { El fin, será lograr una captura } \\
\text { viva del insecto para } \\
\text { identificarlo, se realizará una }\end{array}$ & $\begin{array}{l}\text { Los estudiantes podrán poner } \\
\text { a prueba lo aprendido sobre } \\
\text { los insectos y de esta manera } \\
\text { escogerán nuevamente un } \\
\text { insecto que cumpla con las } \\
\text { características explicadas. }\end{array}$ & $\begin{array}{l}\text { Se proporcionará una guía básica } \\
\text { de identificación de insectos la } \\
\text { cual será de gran ayuda para las } \\
\text { diferentes sesiones. } \\
\text { También, el trabajo práctico } \\
\text { permitirá la elección del insecto } \\
\text { que se va a trabajar durante las } \\
\text { demás sesiones y tener una foto } \\
\text { del mismo. } \\
\text { Trabajo en casa: } \\
\text { Realizar un cuadro donde se } \\
\text { pegue la fotografía del insecto } \\
\text { escogido, se realice una } \\
\text { ilustración lo más fiel posible a la } \\
\text { fotografía, con ayuda de la guía } \\
\text { de identificación de órdenes se } \\
\text { determinará el orden al que } \\
\text { pertenece el insecto capturado, y } \\
\text { consultar las características } \\
\text { propias e importancia de dicho }\end{array}$ \\
\hline
\end{tabular}




\section{Bio - grafía. Escritos sobre la Biología y su Enseñanza. ISSN 2027-1034}

Edición Extraordinaria. p.p. 44 - 83

Memorias del IX Encuentro Nacional de Experiencias en Enseñanza de la Biología y la

Educación Ambiental. IV Congreso Nacional de Investigación en Enseñanza de la Biología.

\begin{tabular}{|c|c|c|c|c|c|}
\hline & & $\begin{array}{l}\text { de Colecciones } \\
\text { Entomológicas. de } \\
\text { Universidad } \\
\text { Antioquia. Medellín, } \\
\text { Colombia. }\end{array}$ & $\begin{array}{l}\text { toma de fotografías para su } \\
\text { próxima identificación. } \\
\text { Terminada la clase, y } \\
\text { teniendo una buena } \\
\text { fotografía del insecto, los } \\
\text { estudiantes liberaran los } \\
\text { especímenes colectados. } \\
\text { Luego de ello, se les } \\
\text { entregará una guía básica de } \\
\text { identificación de órdenes de } \\
\text { la clase insecta (Ver Anexo } \\
\text { 4), para realizar el trabajo en } \\
\text { casa. }\end{array}$ & & orden. \\
\hline 7 & $\begin{array}{l}\text { ¿Cómo y qué } \\
\text { he aprendido } \\
\text { hasta ahora? }\end{array}$ & $\begin{array}{lr}\text { Realizar } & \text { una } \\
\text { evaluación } & \text { que } \\
\text { permita que el } \\
\text { profesor evidencie } \\
\text { que han aprendido } \\
\text { sus estudiantes, en } \\
\text { qué temas se tienen } \\
\text { falencias y que se } \\
\text { debe reforzar. }\end{array}$ & 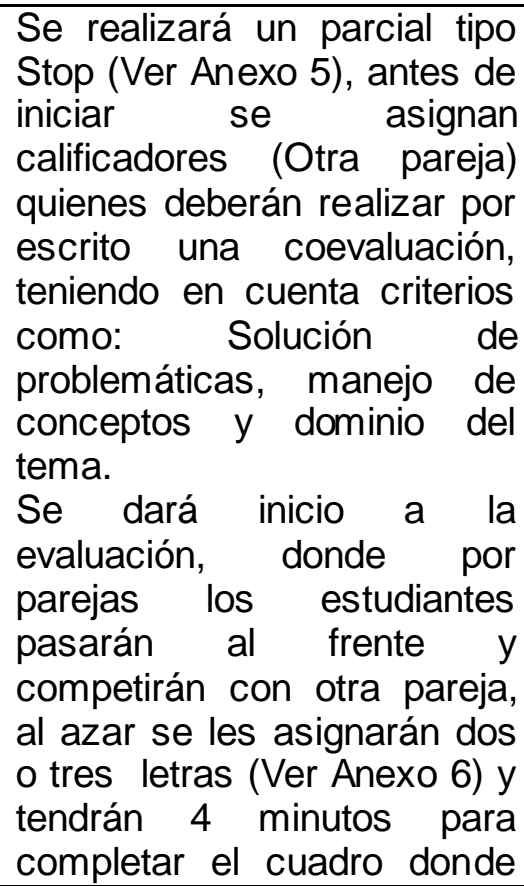 & $\begin{array}{l}\text { Los estudiantes evidenciarán } \\
\text { que tanto han aprendido, su } \\
\text { dominio de conceptos y su } \\
\text { manejo de problemáticas } \\
\text { cotidianas, permitiendo una } \\
\text { retroalimentación al profesor, } \\
\text { para poder reforzar los temas } \\
\text { en los que se tengan } \\
\text { falencias. } \\
\text { También, los estudiantes } \\
\text { pondrán en práctica la } \\
\text { autoevaluación y la } \\
\text { coevaluación, y criterios } \\
\text { importantes para evidenciar su } \\
\text { nivel de comprensión. }\end{array}$ & $\begin{array}{l}\text { Se evidenciarán falencias en las } \\
\text { temáticas trabajadas, esto será } \\
\text { importante para poder reforzarlas } \\
\text { durante las próximas sesiones, } \\
\text { logrando una mayor comprensión } \\
\text { del tema. }\end{array}$ \\
\hline
\end{tabular}

$$
75
$$


Bio - grafía. Escritos sobre la Biología y su Enseñanza. ISSN 2027-1034

Edición Extraordinaria. p.p. 44 - 83

Memorias del IX Encuentro Nacional de Experiencias en Enseñanza de la Biología y la Educación Ambiental. IV Congreso Nacional de Investigación en Enseñanza de la Biología.

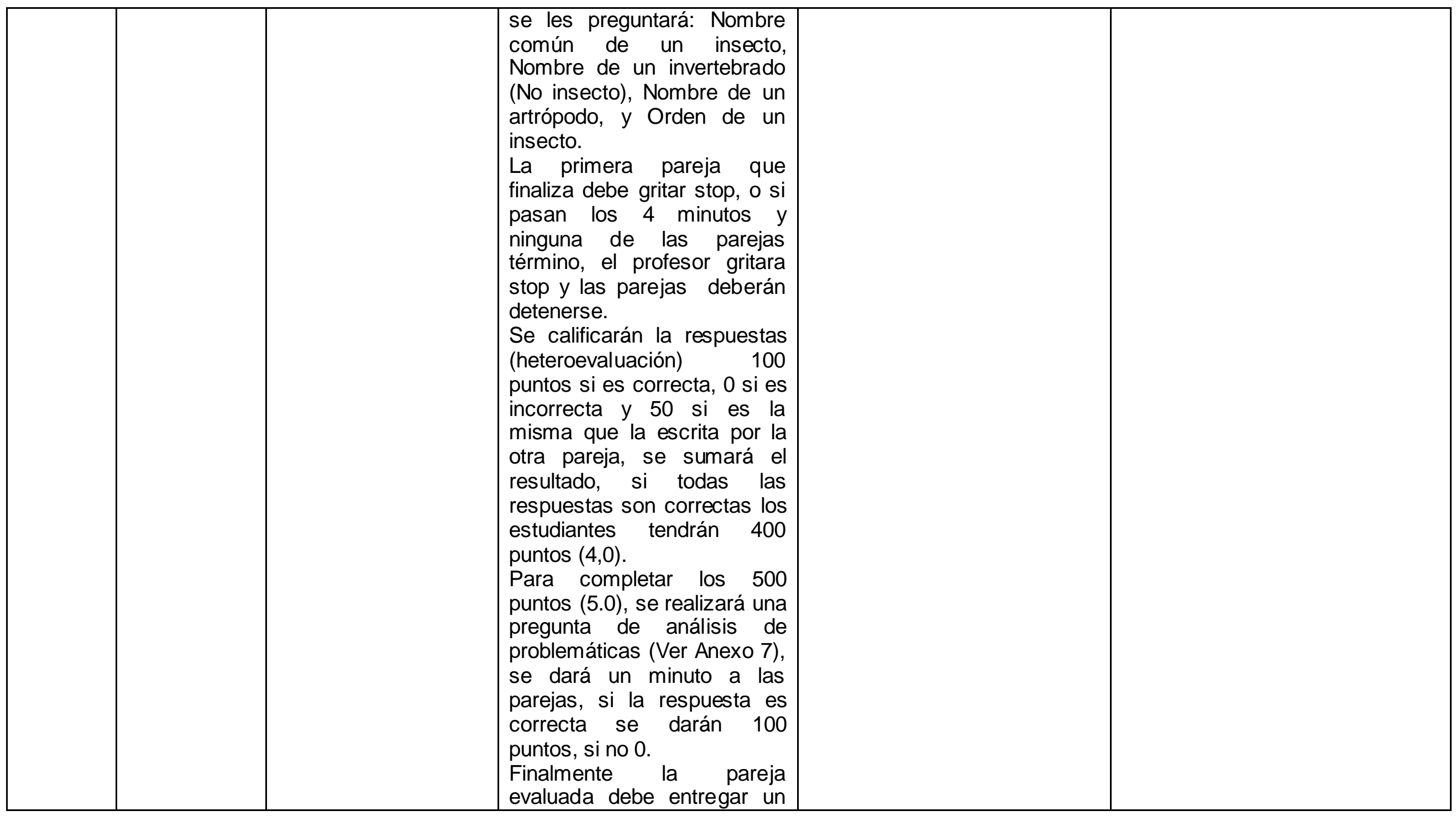


Bio - grafía. Escritos sobre la Biología y su Enseñanza. ISSN 2027-1034

Edición Extraordinaria. p.p. 44 - 83

Memorias del IX Encuentro Nacional de Experiencias en Enseñanza de la Biología y la

Educación Ambiental. IV Congreso Nacional de Investigación en Enseñanza de la Biología.

\begin{tabular}{|c|c|c|c|c|c|}
\hline & & & $\begin{array}{l}\text { hoja con su autoevaluación, } \\
\text { donde se asignará una } \\
\text { valoración de } 0-5,0 \text { y } \\
\text { explicara por qué dicha } \\
\text { valoración. }\end{array}$ & & \\
\hline $8^{*}$ & $\begin{array}{l}\text { ¿Cómo se } \\
\text { organizan y } \\
\text { se clasifican } \\
\text { los } \\
\text { organismos? } \\
\text { ¿Cómo } \\
\text { puede esta } \\
\text { clasificación } \\
\text { aportar al } \\
\text { conocimiento } \\
\text { de la } \\
\text { biodiversidad } \\
?\end{array}$ & 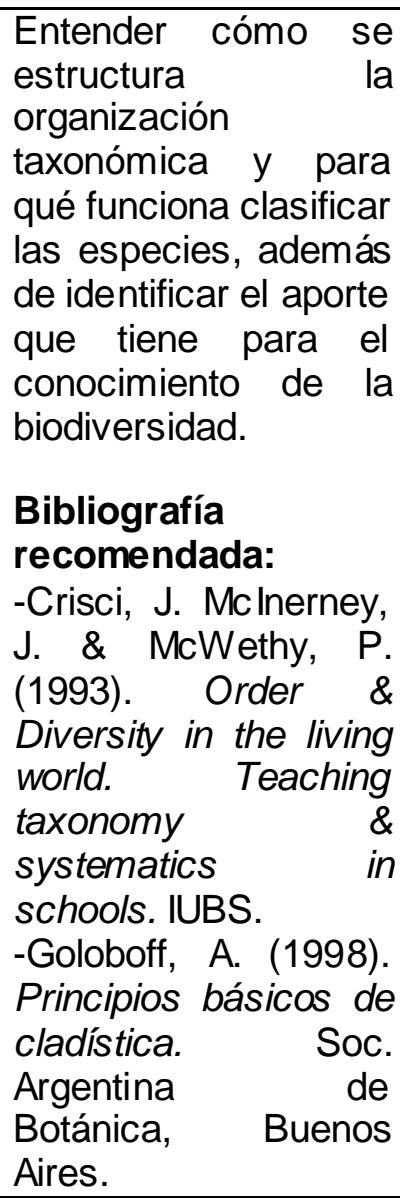 & $\begin{array}{l}\text { Se entregará a los } \\
\text { estudiantes una guía (Ver } \\
\text { Anexo 8) sobre taxonomía y } \\
\text { biodiversidad, donde } \\
\text { deberán responder } \\
\text { preguntas como: ¿Cómo } \\
\text { crees que la taxonomía } \\
\text { puede evitar procesos de } \\
\text { extinción?, Discute con tus } \\
\text { compañeros el concepto de } \\
\text { jerarquización y defínelo con } \\
\text { tus palabras, ¿Cuántos y } \\
\text { cuáles son los dominios de } \\
\text { los seres vivos? ¿En cuál de } \\
\text { las clasificaciones se } \\
\text { agrupan más organismos y } \\
\text { en cual se agrupan menos? } \\
\text { ¿Por Qué?, y ¿Cuáles son } \\
\text { las características de cada } \\
\text { reino? dar } 3 \text { ejemplos por } \\
\text { reino. } \\
\text { También se puede preguntar } \\
\text { específicamente sobre los } \\
\text { insectos: ¿por qué es } \\
\text { importante clasificar los } \\
\text { insectos en un país como } \\
\text { Colombia? }\end{array}$ & $\begin{array}{l}\text { Los estudiantes podrán } \\
\text { complementar sus } \\
\text { conocimientos en taxonomía y } \\
\text { entender por qué fue } \\
\text { necesario clasificar su insecto } \\
\text { hasta orden. }\end{array}$ & $\begin{array}{l}\text { Será importante para el proyecto } \\
\text { síntesis que el estudiante } \\
\text { entienda cómo las características } \\
\text { morfológicas e incluso genéticas } \\
\text { pueden agrupar a sus } \\
\text { organismos, de queriendo } \\
\text { representar de forma más } \\
\text { detallada aquellas características } \\
\text { propias de su insecto. }\end{array}$ \\
\hline
\end{tabular}




\section{Bio - grafía. Escritos sobre la Biología y su Enseñanza. ISSN 2027-1034}

Edición Extraordinaria. p.p. 44 - 83

Memorias del IX Encuentro Nacional de Experiencias en Enseñanza de la Biología y la

Educación Ambiental. IV Congreso Nacional de Investigación en Enseñanza de la Biología.

\begin{tabular}{|c|c|c|c|c|c|}
\hline 9 & $\begin{array}{l}\text { ¿Cómo } \\
\text { vamos } \\
\text { relacionando } \\
\text { lo } \\
\text { aprendido? } \\
\text { ¿Cómo } \\
\text { vamos a } \\
\text { seguir } \\
\text { avanzando } \\
\text { en nuestro } \\
\text { proceso? }\end{array}$ & $\begin{array}{l}\text { Será importante } \\
\text { realizar una sesión de } \\
\text { explicación y } \\
\text { resolución de } \\
\text { problemas, para que } \\
\text { el estudiante siga } \\
\text { hilando el proceso y } \\
\text { entienda como se } \\
\text { apunta al proyecto } \\
\text { síntesis. }\end{array}$ & 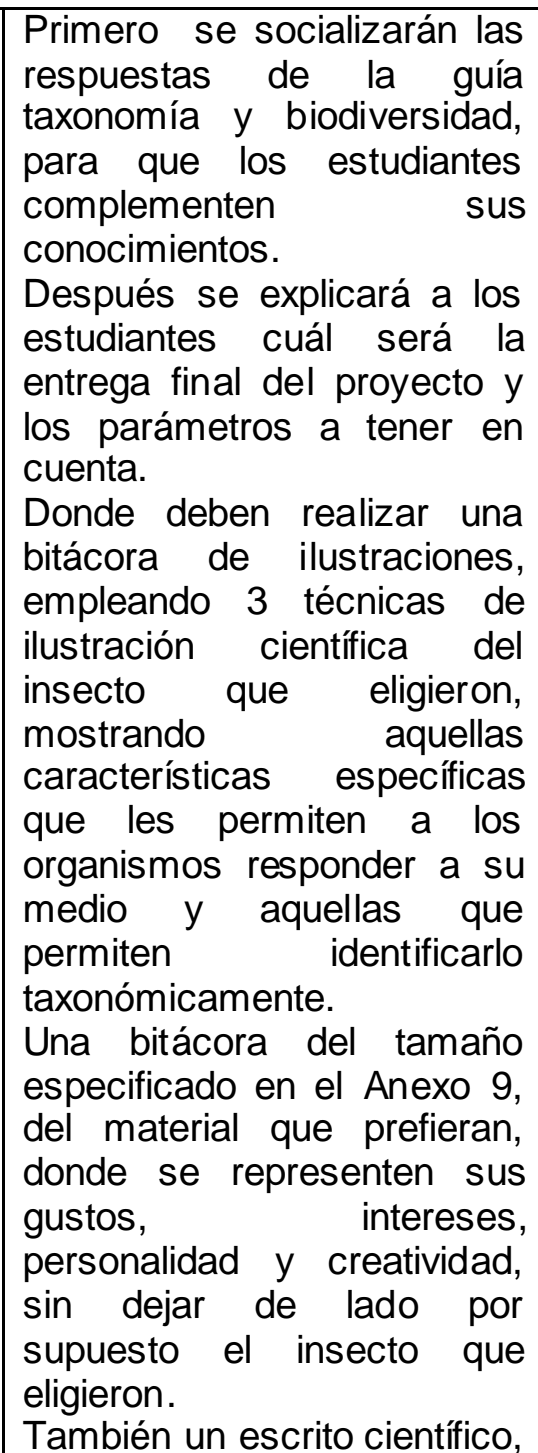 & $\begin{array}{l}\text { Los estudiantes podrán } \\
\text { reconocer de manera más } \\
\text { clara el proyecto síntesis, se } \\
\text { podrán resolver sus dudas, } \\
\text { también podrán conocer el } \\
\text { modo en que serán evaluados } \\
\text { y las fechas de interés. }\end{array}$ & 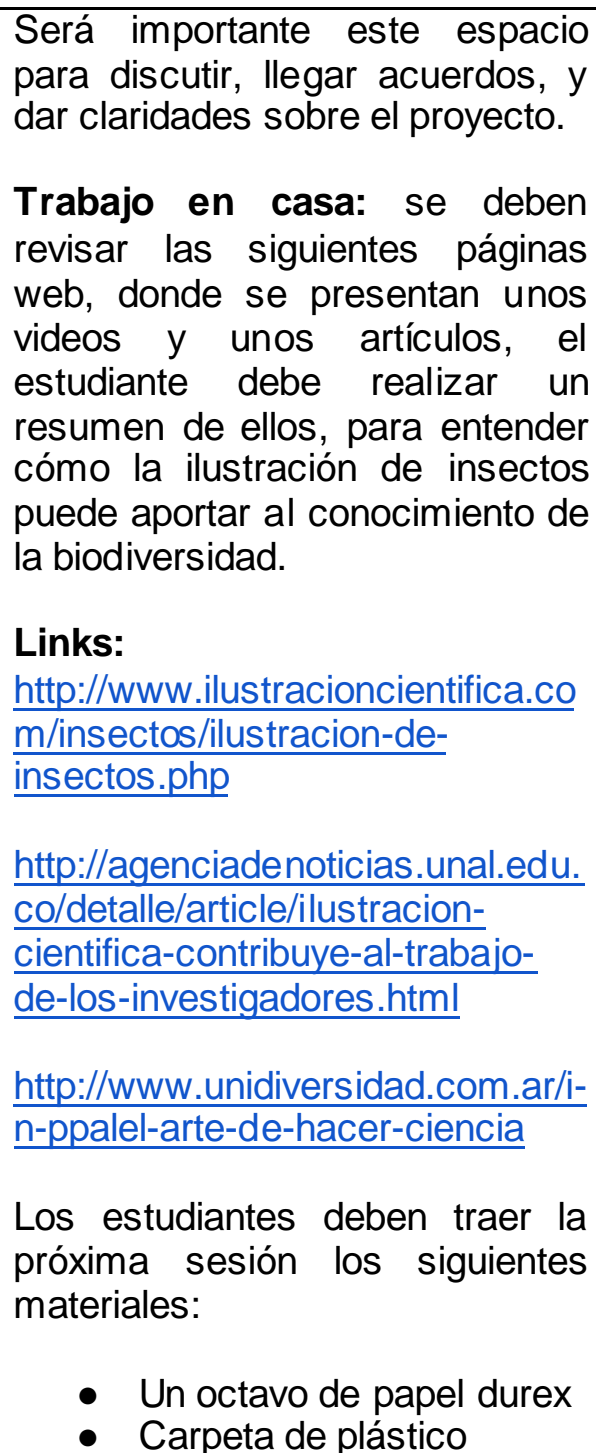 \\
\hline
\end{tabular}


Bio - grafía. Escritos sobre la Biología y su Enseñanza. ISSN 2027-1034

Edición Extraordinaria. p.p. 44 - 83

Memorias del IX Encuentro Nacional de Experiencias en Enseñanza de la Biología y la

Educación Ambiental. IV Congreso Nacional de Investigación en Enseñanza de la Biología.

\begin{tabular}{|c|c|c|c|c|c|}
\hline & & & $\begin{array}{l}\text { donde no solo se presenta la } \\
\text { taxonomía del organismo, si } \\
\text { no las características que } \\
\text { permiten clasificarlo, las } \\
\text { relaciones que presentan con } \\
\text { el medio, la importancia } \\
\text { ecosistémica que tengan, la } \\
\text { explicación de la estructuras } \\
\text { externas e internas que le } \\
\text { permiten responder a su } \\
\text { medio, y finalmente el ciclo } \\
\text { de vida del organismo, este } \\
\text { escrito tiene como intención } \\
\text { recopilar todos los } \\
\text { conocimientos conceptuales } \\
\text { que se han comprendido. } \\
\text { Se darán fechas de entrega, } \\
\text { lo ideal es que el escrito } \\
\text { tenga dos entregas, para } \\
\text { poder retroalimentar y dar } \\
\text { sugerencia a los estudiantes. }\end{array}$ & & $\begin{array}{ll}\text { - } & \text { Lápices 2B y 4B } \\
\text { - } & \text { Limpia tipos } \\
\text { - } & \text { Borrador miga de pan } \\
\text { - } & \text { Tajalápiz } \\
\text { - Regla }\end{array}$ \\
\hline 10 & $\begin{array}{l}\text { ¿Qué es la } \\
\text { ilustración } \\
\text { científica y } \\
\text { como puedo } \\
\text { emplearla } \\
\text { para } \\
\text { representar } \\
\text { mi insecto? }\end{array}$ & \begin{tabular}{lr} 
Breve & \multicolumn{2}{r}{ reseña } \\
histórica sobre la \\
ilustración científica y \\
la importancia en la \\
biología. \\
practicara Se \\
bocetación y y se \\
realizará la primera \\
ilustración en grafito \\
del insecto.
\end{tabular} & $\begin{array}{l}\text { Se explicara la forma } \\
\text { adecuada de hacer el boceto } \\
\text { de su insecto, teniendo como } \\
\text { guía las fotografías tomadas } \\
\text { en la huerta, o fotografías de } \\
\text { internet }\end{array}$ & & $\begin{array}{l}\text { El estudiante va adquirir } \\
\text { conocimientos sobre bocetación, } \\
\text { que será indispensable para la } \\
\text { realización de las ilustraciones. } \\
\text { Tarea para la casa: Terminar la } \\
\text { ilustración a grafito. }\end{array}$ \\
\hline 11 & ¿Cómo & Sentido & Se realizan grupos de 4 & Los estudiantes desarrollaran & Trabajo en casa: \\
\hline
\end{tabular}




\section{Bio - grafía. Escritos sobre la Biología y su Enseñanza. ISSN 2027-1034}

Edición Extraordinaria. p.p. 44 - 83

Memorias del IX Encuentro Nacional de Experiencias en Enseñanza de la Biología y la

Educación Ambiental. IV Congreso Nacional de Investigación en Enseñanza de la Biología.

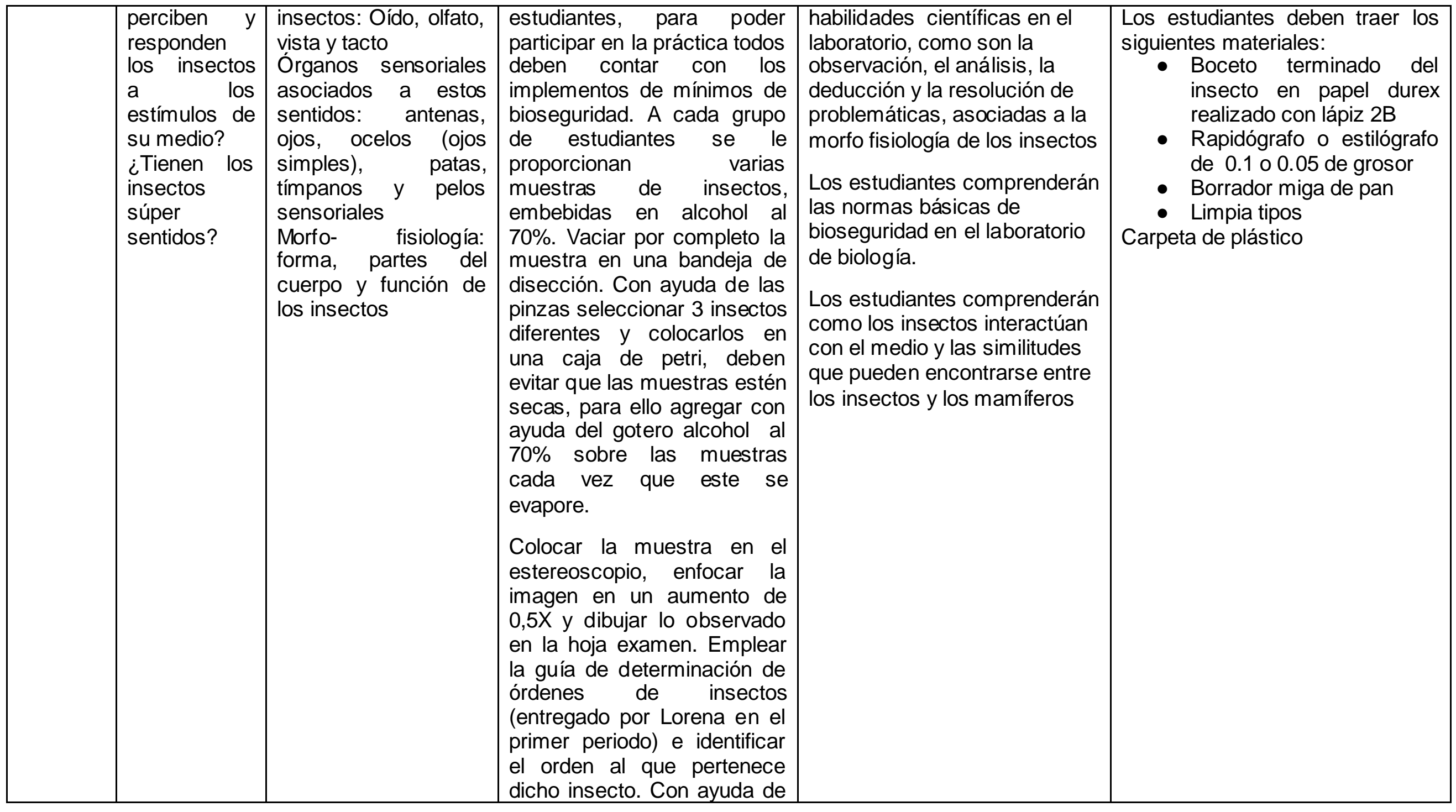


Bio - grafía. Escritos sobre la Biología y su Enseñanza. ISSN 2027-1034

Edición Extraordinaria. p.p. 44 - 83

Memorias del IX Encuentro Nacional de Experiencias en Enseñanza de la Biología y la Educación Ambiental. IV Congreso Nacional de Investigación en Enseñanza de la Biología.

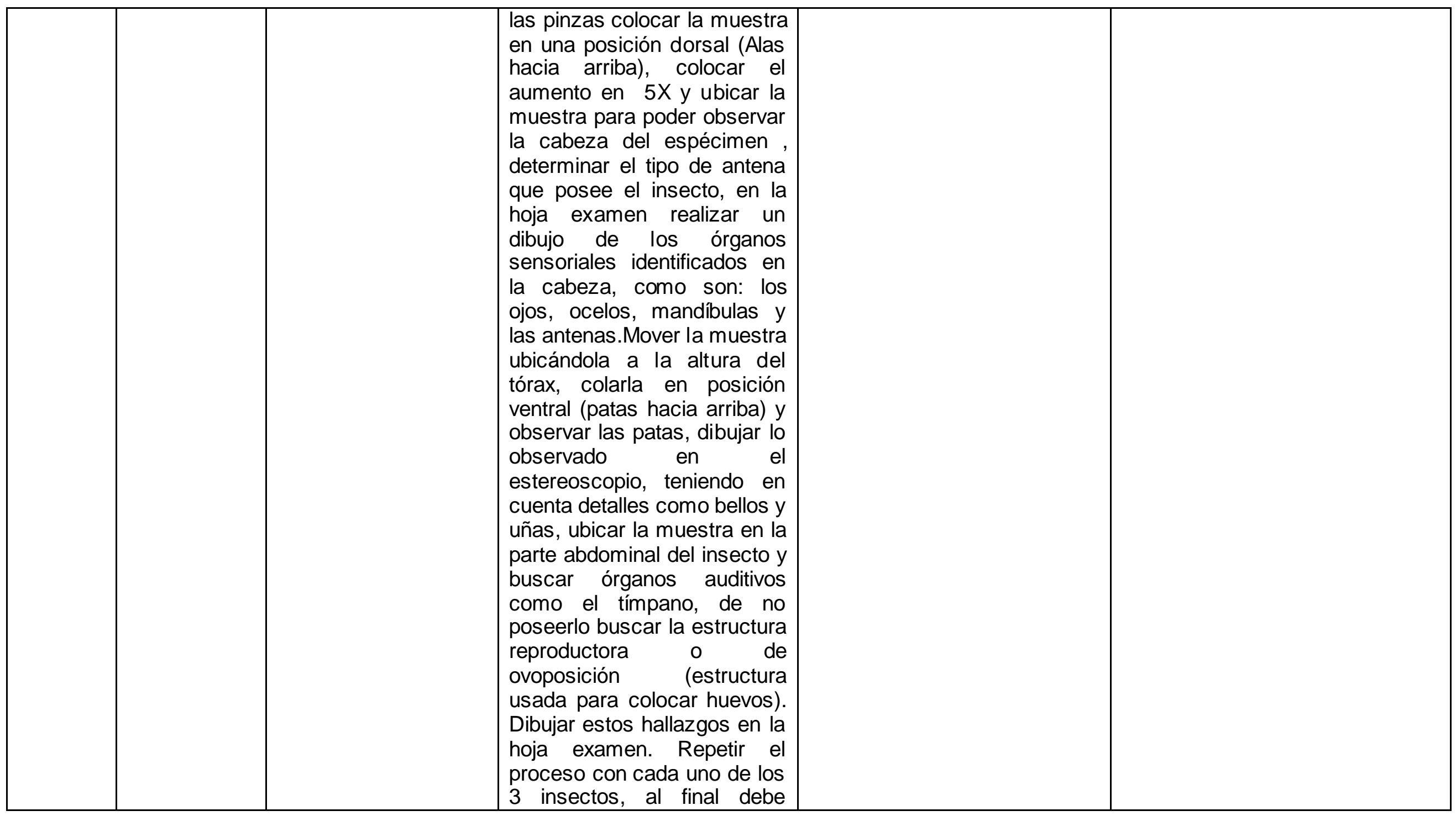


Bio - grafía. Escritos sobre la Biología y su Enseñanza. ISSN 2027-1034

Edición Extraordinaria. p.p. 44 - 83

Memorias del IX Encuentro Nacional de Experiencias en Enseñanza de la Biología y la

Educación Ambiental. IV Congreso Nacional de Investigación en Enseñanza de la Biología.

\begin{tabular}{|c|c|c|c|c|}
\hline & & & $\begin{array}{l}\text { entregar la hoja examen con } \\
\text { los respectivos dibujos, } \\
\text { donde muestre cada uno de } \\
\text { los órganos asociados al } \\
\text { gusto, a la vista, al tacto, al } \\
\text { oído y al olfato. }\end{array}$ & \\
\hline 12 & $\begin{array}{l}\text { ¿Cómo } \\
\text { puedo } \\
\text { emplear el } \\
\text { puntillismo } \\
\text { para } \\
\text { representar } \\
\text { las } \\
\text { estructuras } \\
\text { sensoriales } \\
\text { de los } \\
\text { insectos? }\end{array}$ & & & $\begin{array}{l}\text { Trabajo para la casa: } \\
\text { Terminar la ilustración con la } \\
\text { técnica de puntillismo. }\end{array}$ \\
\hline 13 & $\begin{array}{l}\text { ¿Qué } \\
\text { importancia } \\
\text { tienen los } \\
\text { insectos en } \\
\text { la huerta y } \\
\text { en el } \\
\text { mundo? } \\
\text { ¿Por qué se } \\
\text { deben } \\
\text { valorar y } \\
\text { cuidar estos } \\
\text { insectos? }\end{array}$ & $\begin{array}{l}\text { Entender la } \\
\text { importancia ecológica } \\
\text { que tienen los } \\
\text { insectos, no solo en la } \\
\text { huerta si no en el } \\
\text { mundo, recalcando } \\
\text { las características } \\
\text { que han hecho a este } \\
\text { grupo el más exitoso } \\
\text { del reino animal y que } \\
\text { sean fundamentales } \\
\text { para la vida en la } \\
\text { tierra. }\end{array}$ & & $\begin{array}{l}\text { Tarea para la casa: } \\
\text { Los estudiantes deben traer los } \\
\text { siguientes materiales: } \\
\text { - Boceto terminado del } \\
\text { insecto en papel durex } \\
\text { elaborado con lápiz 2B } \\
\text { - Colores } \\
\text { - Borrador miga de pan } \\
\text { - Limpia tipos } \\
\text { - Tajalápiz } \\
\text { - Difumino } \\
\text { - Carpeta de plástico } \\
\end{array}$ \\
\hline 14 & $\begin{array}{l}\text { ¿Cómo } \\
\text { puedo utilizar }\end{array}$ & & & $\begin{array}{l}\text { Trabajo para la casa: } \\
\text { Terminar la ilustración con la }\end{array}$ \\
\hline
\end{tabular}


Bio - grafía. Escritos sobre la Biología y su Enseñanza. ISSN 2027-1034

Edición Extraordinaria. p.p. 44 - 83

Memorias del IX Encuentro Nacional de Experiencias en Enseñanza de la Biología y la Educación Ambiental. IV Congreso Nacional de Investigación en Enseñanza de la Biología.

\begin{tabular}{|l|l|l|l|l|}
\hline la técnica & & & técnica lápices de colores. \\
lápices de & & Consultar el ciclo de vida de \\
colores para & insecto y consultar como es el \\
para mostrar & & & sistema nervioso de un insecto. \\
las & & \\
relaciones & & & \\
del insecto & & & \\
con su & & & \\
\hline
\end{tabular}

